\title{
Comparative phylogeography reveals how a barrier filters and structures taxa in North American warm deserts
}

\author{
Kaiya L. Provost ${ }^{1,2, *}$, Edward A. Myers ${ }^{3}$, Brian Tilston Smith ${ }^{1}$
}

${ }^{1}$ Department of Ornithology, American Museum of Natural History, New York, New York

${ }^{2}$ Richard Gilder Graduate School, American Museum of Natural History, New York, New York

${ }^{3}$ Department of Vertebrate Zoology, National Museum of Natural History, Washington, District of Columbia

${ }^{*}$ Corresponding author: Kaiya L. Provost, Department of Ornithology, American Museum of Natural History, New York, New York; Email address: kprovost@amnh.org

\begin{abstract}
The study of biogeographic barriers have been instrumental in understanding the evolution and distribution of taxa. Now with the increased availability of empirical datasets, it is possible to infer emergent patterns from communities by synthesizing how barriers filter and structure populations across species. We assemble phylogeographic data for a barrier and perform spatially-explicit simulations to quantify temporal and spatial patterns of divergence, the influence of species traits on these patterns, and understand the statistical power of differentiating alternative diversification modes. We incorporate published datasets to examine taxa around the Cochise Filter Barrier, separating the Sonoran and Chihuahuan deserts of North America, to synthesize phylogeographic structuring across the community with respect to organismal functional traits. We then use a simulation and machine learning pipeline to assess the power of phylogeographic model selection. Taxa distributed across the Cochise Filter Barrier show heterogeneous responses to the barrier in levels of gene flow, phylogeographic structure, divergence timing, barrier width, and divergence mechanism. These responses vary concordantly with locomotor and thermoregulatory traits. Many taxa show a Pleistocene population genetic break, often with introgression after divergence. Allopatric isolation and isolation-by-environment are the primary mechanisms purported to structure taxa. Simulations reveal that in spatially-explicit isolation-with-migration models across the barrier, age of divergence, presence of gene flow, and presence of isolation-by-distance can confound the interpretation of evolutionary history and model selection by producing easily-confusable results. By synthesizing phylogeographic data for the Cochise Filter Barrier we show a pattern where barriers interact with species traits to differentiate taxa in communities over millions of years. Identifying the modes of differentiation across the barriers for these taxa remains challenging because commonly invoked demographic models may not be identifiable across a range of likely parameter space.
\end{abstract}

Keywords: biogeographic barrier, comparative phylogeography, functional traits, genetic diversity, isolation-by-distance, isolation-with-migration, neural net 


\section{Introduction}

Biogeographic barriers, which separate taxa and restrict gene flow via unsuitable habitat or impeded dispersal, have shaped the fields of evolutionary biology and ecology (e.g., Simpson, 1940; Lomolino, Sax, and Brown, 2004). Observing spatially disjunct taxa led to development of theory in species concepts (e.g., Mayr, 1942; de Queiroz, 2005), island biogeography (e.g., Janzen, 1967; MacArthur and Wilson, 1967), hybridization (e.g., Hoskin, Higgie, McDonald, and Moritz, 2005), and taxonomy (e.g., Helbig, Knox, Parkin, Sangster, and Collinson, 2002). The unifying factor across these disciplines is that the barrier itself is directly or indirectly linked to the process that generated the pattern of interest. Understanding the mechanisms that produce these patterns has been a major focus in historical biogeography, and efforts have expanded with the increasing number and complexity of phylogeographic studies (see Garrick et al., 2015).

Phylogeography has the dual aim of characterizing how diversity is distributed across the landscape and proposing the temporal framework for when the diversity formed (Avise et al., 1987). In addition, phylogeographic approaches aim to infer the processes that have promoted genetic diversity across the landscape (Avise, Bowen, and Ayala, 2016). Early studies provided insight into the distribution of genetic variation within species and species complexes that often coincided with geographic features or environmental gradients (e.g., Taberlet and Bouvet, 1994; Kozak, Blaine, and Larson, 2005). The extension of phylogeographic approaches with advances of molecular dating yielded insight into the timing of divergence between populations (e.g., Fouquet et al., 2010; Matos et al., 2016). Further advancements in DNA sequencing technology and statistical modeling allowed researchers better identify the patterns and processes associated with biogeographic barriers (Hickerson et al., 2010). However, the study of species diversification across barriers has been hampered by conceptual and logistical challenges. One such challenge is that although many taxa might show phylogeographic structure that is concordant with a barrier, this does not indicate that the barrier itself caused the genetic differentiation. For example, processes such as speciation over environmental gradients (Nosil, 2008; but see Bierne, Gagnaire, and David, 2013), behavioral selection (Zhang et al., 2012), or abundance troughs (Barton and Hewitt, 1981; Barrowclough, Groth, Mertz, and Gutierrez, 2005) could all produce similar patterns.

A second challenge is that a barrier may cause differentiation in some taxa, but it may not affect the entire biota at once; this is known as a barrier being semi-permeable or having filters (Simpson, 1940). Filters are hypothesized to be mediated by organismal traits such as morphology (Dick, Hardy, Jones, and Petit, 2008; Hanson, Fuhrman, Horner-Devine, and Martiny, 2012), reproductive isolation (Christe et al., 2016; Provost, Mauck, and Smith, 2018), physiology and niche (Castoe, Spencer, and Parksinson, 2007; Edwards, Lloyd, and Armbruster 2018), or population demographics and drift (Carnicer, Brotons, Stefanescu, and Penuelas, 2012). The mechanisms potentially underlying filter barriers are numerous, possibly barrier- and taxon-specific, and likely not mutually exclusive. Identifying which traits are important for causing isolation requires knowing which taxa are and are not separated at a barrier, where the barrier is relative to phylogeographic breaks between populations, and what functional traits are correlated with differentiation across the filter. To illuminate the actual role of filter barriers in diversification, and the mechanisms causing it, an understanding of the processes of differentiation and variation in the context of communities is required.

Advances in demographic modeling has enabled phylogeographers to distinguish between alternative modes of population differentiation (e.g., Gutenkunst, Hernandez, 
Williamson, and Bustamante, 2009; Gravel, 2012). Many of these approaches must manage computation expense while maximizing the information used (e.g., full likelihood methods, Bayesian methods) or alternately running quickly using approximate methods but requiring large amounts of summary statistics that may not use all of the data collected (e.g., ABC; Hickerson, Stahl, and Lessios, 2006; Jackson, Morales, Carstens, and O'Meara, 2017). New approaches allow testing demographic models on multiple taxa simultaneously (Satler and Carstens, 2017; Xue and Hickerson, 2017) and incorporating species abundances (Overcast, Emerson, and Hickerson, 2019). A common outcome of demographic analyses is overwhelming support for isolation-with-migration models (Nosil, 2008; but see Cruickshank and Hahn, 2014), which has two important implications. First, support for isolation-with-migration over pure allopatry challenges the view that differentiation is a discrete event. Second, filtering dynamics of barriers are likely more complex than recognized if gene flow occurs across them. Gene flow between diverging populations erodes the signal of that divergence by homogenizing the genome (see Eckert and Carstens, 2008), so estimating whether it has occurred is essential in detecting if divergence originally happened. Though detecting the timing and magnitude of gene flow is critical, using demographic model selection to do this can be difficult as models can often be indistinguishable (Roux et al., 2016). Further, most models assume that populations are panmictic, despite the prevalence of isolation-by-distance (IBD), and violating the assumptions of the model may compromise inference (Battey, Ralph, and Kern, 2020). Accounting for IBD in models is now relatively straightforward using the suite of recently developed spatially-explicit methods (e.g., Bradburd, Coop, and Ralph, 2018; Currat, Arenas, Quilodràn, Excoffier, and Ray, 2019), especially when combined with sophisticated statistical analyses like machine learning.

Machine learning approaches relieve some of the statistical and computational burdens of demographic model selection by processing large amounts of data unconstrained by assumptions like data normality (Ripley, 1996). One type of machine learning that is particularly powerful for but underused in evolutionary biology is supervised machine learning, because it can incorporate what is already known about the data when making inferences (Schrider and Kern, 2018). Combined with simulation software developed over the past decades (e.g., Hickerson, Stahl, and Takebayashi, 2007; Gutenkunst et al., 2009), the phylogeographer has a powerful toolkit for estimating the evolutionary histories of their study groups.

Here, we use an exemplar biogeographic system, the Cochise Filter Barrier (CFB; Fig. 1), to explore the community-wide impact of a barrier on genetic differentiation within species, which traits mediate phylogeographic structure, and what analytical tools have been used to estimate those impacts. The CFB is a well-studied environmental and physical barrier that corresponds with a known transition zone between two biotas (Remington, 1968; Swenson and Howard, 2005) that divides the Sonoran and Chihuahuan Deserts of North America. Dynamic geological and ecological factors created this barrier, though the timing of the formation of the deserts is disputed (Wilson and Pitts, 2010). The southern region of the CFB dates back to the uplift of the Sierra Madre Occidental during the Oligo-Miocene, whereas the northern formed during the Plio-Pleistocene glacial cycles (Van Devender, 1990; Holmgren, Norris, and Betancourt, 2007) and the uplift of the Colorado Plateau (Spencer, 1996). In the north, xeric habitat connecting the deserts was ephemeral during the Plio-Pleistocene, with glacial advances repeatedly replacing aridlands with forests (Thompson and Anderson, 2000; Hafner and Riddle, 2011). This likely created desert refugia east and west of the CFB. Environmental gradients also exist between the hotter, wetter Sonoran Desert and the cooler, dryer Chihuahuan Desert, 
including elevational and vegetational differences and a high altitude grassland plain between the two (Shreve, 1942; Reynolds, Kemp, Ogle, and Fernández, 2004; Figure 1). Interactions between the environment, landscape, and organisms gave rise to the region's biodiversity; some taxa are continuously distributed with no evidence of differentiation, while others show strong phylogeographic structure across the CFB (e.g., Zink, Kessen, Line, and Blackwell-Rago, 2001; Riddle and Hafner, 2006). The barrier is not one sharp break; rather, the biota is thought to turn over approximately between $112-108^{\circ} \mathrm{W}$ longitude (Pyron and Burbrink, 2010; Hafner and Riddle, 2011). The barrier is also associated with the Western Continental Divide (Castoe et al., 2007). Despite this, there is no quantitative estimate of the position and width of the barrier across taxa. Without understanding this, it is difficult to infer whether taxa have all been impacted by the same filter and which organismal traits may have been selectively advantageous for crossing the barrier and maintaining gene flow. It is also unclear when divergence happened, with estimates of population divergence ranging from the Miocene through the Pleistocene (e.g., Myers, Hickerson, and Burbrink, 2017), or whether dispersal occurred after lineage formation. Knowing when and where taxa diversify can lead to inferences on the processes that cause the initial divergence between populations, as well as further insights on post-divergence gene flow and the impact of IBD within structured lineages.

We describe the diversity in genetic structure in taxa across the CFB. We synthesize what phylogeographic analyses have been used to understand the system (e.g., divergence dating, estimates of gene flow), which taxa are separated at the CFB, where the separation is, and when divergence occurred. We ask whether the location, age, and width of the barrier are consistent across taxa, because discrepancies can illuminate the filtering mechanisms that structure organisms. Further, we ask if variation in functional traits corresponds with the presence of phylogeographic structure. Under a dispersal limitation hypothesis, the vagility of organisms should be correlated with how much phylogeographic structure they display. A barrier should have a stronger impact on less vagile organisms. Under a thermoregulatory hypothesis, we expect that the ability of an organism to regulate their body temperature should be correlated with phylogeographic structure. Ectotherms may be more affected by environmental filters and more likely to experience reduced gene flow in the face of spatiotemporal climatic changes. We simulate genomic data under competing diversification scenarios across the CFB to determine whether genomic datasets and demographic models can further clarify how diversification proceeded. We aim to describe how synthesizing across empirical, theoretical, and simulated phylogeographic studies can lead to novel insights about the mechanisms of divergence across biogeographic barriers. 


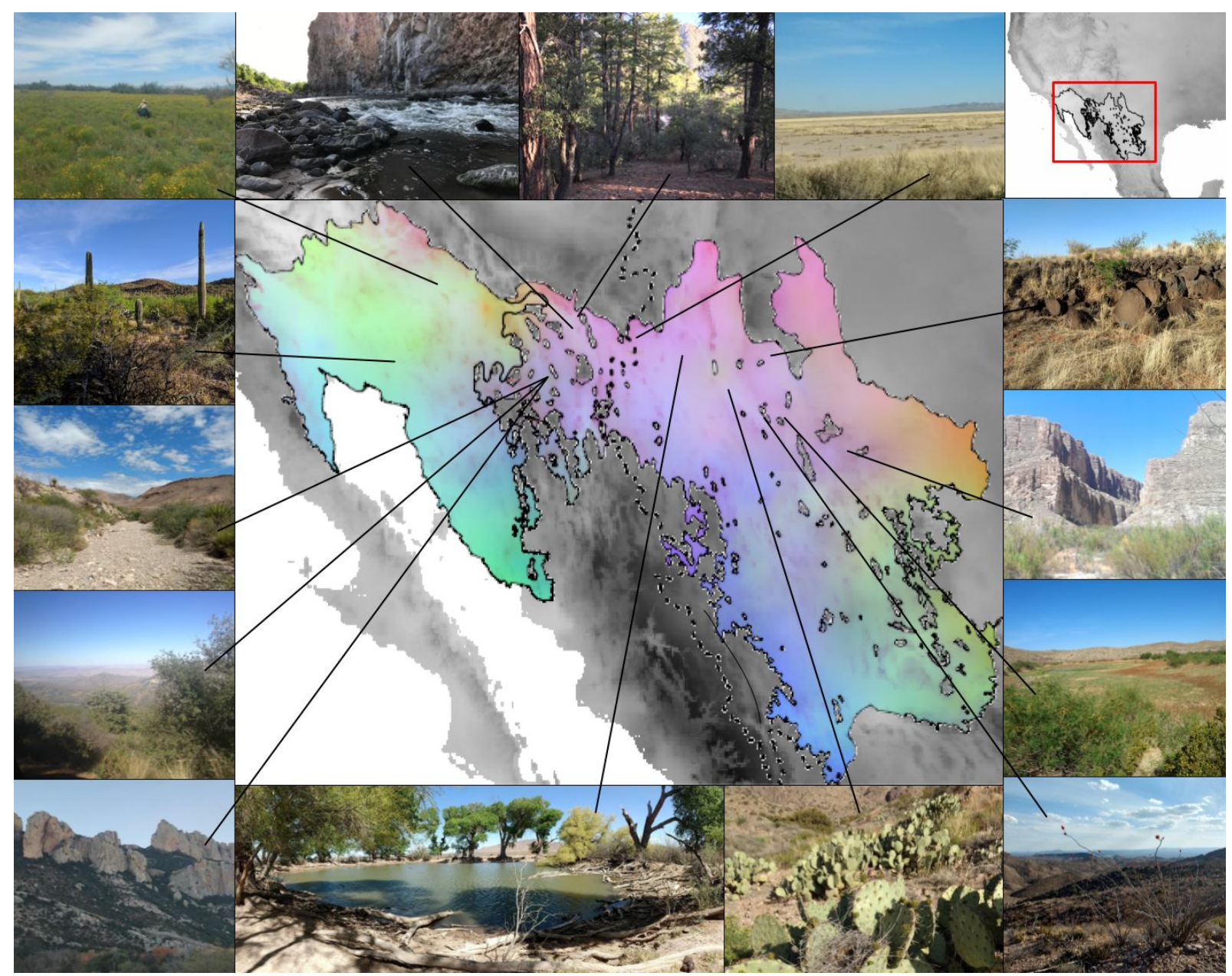

Figure 1: Examples of habitat and climatic variation in the Sonoran and Chihuahuan deserts. Center shows Sonoran and Chihuahuan desert outlines (Olson et al., 2001) and dotted line indicates the Western Continental Divide. Colors represent results of a PCA of climatic variables (see Appendix 1), with the first three principal components mapped to green, red, and blue channels of the image, respectively. More green indicates hotter summer temperatures. More red indicates more variable temperatures across the year. More blue indicates more summer precipitation. Areas outside of the deserts are the same principal components converted to grayscale. Top right shows the section of North America that the center region displays. Photographs around the map show representative habitats across the region, with a line leading to the point on the map where the photograph was taken.

\section{Methods}

\section{Characterizing phylogeographic breaks across the CFB}

Understanding the filtering mechanisms operating on taxa distributed across barriers requires understanding where phylogeographic breaks are and which taxa are impacted. To quantify the patterns and frequency of modes of divergence across the CFB, we synthesize genetic patterns from published phylogeographic studies with inter- and intraspecific sampling across the CFB. We recorded the publication date of each study, data type (e.g., single-locus, SNP, etc.), and number of loci. Finally, we characterized each taxon based on their type of locomotion (following Burbrink et al., 2016) and type of thermoregulation (endo- vs ectothermic) to assess whether these traits interacted with the filter to impact the degree of population structuring. We also quantified elevational preference (lowland, montane, or both) to control for elevational differences on diversification. To assess the effects of traits on divergence 
times, we performed generalized linear mixed modeling (GLMMs) via the 'LME4' package version 1.1-21 (Bates, Mächler, Bolker, and Walker, 2015) in R version 3.6.1 (R Core Team, 2019) with and without accounting for taxonomy and elevation (see Appendix 1 for supplementary analyses).

For each taxon, we examined if a specific mode of diversification across the barrier was implicated by the authors of the respective studies (i.e., allopatry, ecological, hybridization, sexual selection, or polyploidy). Second, we assessed whether there was phylogeographic structure across the CFB, when structure arose, and if populations were reciprocally monophyletic with respect to individual loci. Because of the ambiguity in the placement of the CFB we chose to characterize whether there was a phylogeographic break between $118-99^{\circ} \mathrm{W}$ longitude, a much larger range than previously thought (Pyron and Burbrink, 2010; Hafner and Riddle, 2011; Myers et al., 2019). In addition, we assessed the width of the contact zone for each taxon by taking the localities of specimens used in each study, or if specimen information was not available, by assessing placement of specimens on figures. We ignored other biogeographic breaks known to occur within the species' ranges. Missing data for variables not estimated for a given taxon were coded as ambiguous.

To determine when phylogeographic structure formed, we categorized the divergence time between the desert populations by epoch: Pleistocene (2.58 Ma to $11.7 \mathrm{Ka})$, Pliocene $(5.33$ Ma to $2.58 \mathrm{Ma}$ ), Miocene (23.0 Ma to to $5.33 \mathrm{Ma}$ ), or overlapping two epochs. We separated dates by epoch to allow broad comparisons in divergence across the community. Some studies suggested epochs of divergence between populations without explicit estimates of the divergence date, which we noted. When applicable, we included the full range of error around an estimate. In addition, to assess whether taxa were monophyletic with respect to the CFB, we visually assessed gene trees present in the study. Finally, we assessed whether gene flow across the barrier was explicitly estimated. If gene flow was not explicitly estimated, we considered individuals who show admixture in clustering analyses as a proxy for gene flow; we recognize that a high coefficient of ancestry could result from incomplete lineage sorting of ancestral polymorphisms. We then recorded whether gene flow was present, absent, or ambiguous.

\section{Simulation of discrete population structure and IBD}

From our assessment of the literature across the CFB, two patterns were consistently found: discrete phylogeographic structure, or IBD without a discrete transition between populations. However, it is possible that both of these patterns are simultaneously observable in empirical population genetic data (Bradburd et al., 2018) and could be distinguished using a simulation-based approach. We used the program SLiM 3.1 (Haller and Messer, 2019) to build models that explored how the processes of allopatric isolation and speciation-with-gene-flow interact to generate divergence across a biogeographic barrier.

First, we simulated four demographic models, which varied by genetic structure and introgression: 1) a single population model, in which only one panmictic population exists across the entire region, 2) a pure isolation model, in which two populations exist but no gene flow is allowed between them, 3) an isolation-with-migration model, as in pure isolation but allowing gene flow continuously between the populations at a low rate, and 4) a secondary contact model, with gene flow allowed during the final 1,000 generations of the simulation (Figure 2). We chose 1,000 generations of the simulation to represent late-Holocene secondary contact. These four models represent different underlying processes of diversification that are commonly tested for 
in phylogeographic studies, and with them we evaluated how gene flow and divergence across the CFB varied.

Second, we simulated the presence of IBD to test whether it would impede our ability to determine phylogeographic structure. When IBD was implemented in a model, simulated individuals could only mate and produce offspring with their nearest neighbors. In isolation-with-migration models, gene flow could only occur between individuals close to the contact zone. In contrast, if IBD was not implemented, individuals could choose any other member of the population to produce offspring with, irrespective of geographic distance. These models were spatially-explicit with respect to both the environment that individuals were simulated on and mate choice and production of offspring (see Appendix 1).

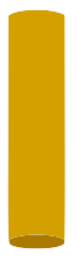

M1

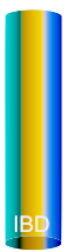

M2

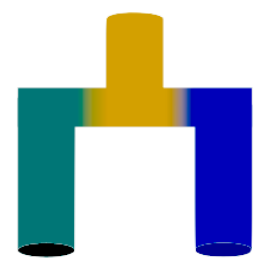

M3

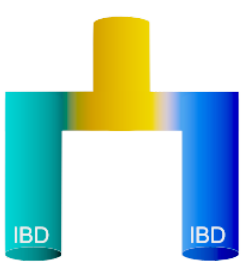

M4

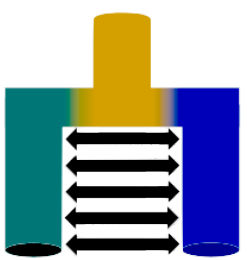

M5

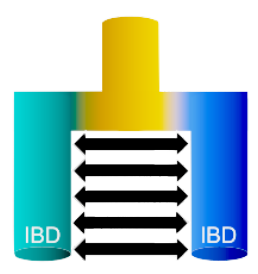

M6

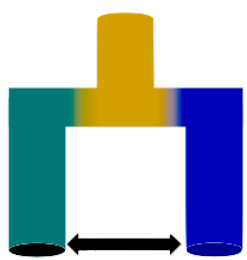

M7

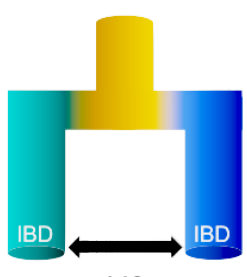

M8

Figure 2: Visualization of the eight models simulated. Colorful tubes indicate populations. Arrows indicate gene flow. Color gradients within tubes indicate the presence of IBD, while solid colored tubes indicate no IBD. M1: Single population without IBD. M2: Single population with IBD. M3: Isolation without IBD. M4: Isolation with IBD. M5: isolation-with-migration without IBD. M6: isolation-with-migration with IBD. M7: Secondary contact without IBD. M8: Secondary contact with IBD.

We simulated four different lengths of time: 6,000, 21,000, 120,000, and 1,000,000 generations. These approximately correspond to the mid-Holocene, last interglacial optimum, last glacial maximum, and mid-Pleistocene, assuming a generation time of one year. We chose to use different time frames to 1) test if we could tell apart the different models when divergence times were short, 2) investigate divergence times that could have taken place during major environmental shifts in the $\mathrm{CFB}$ region, and reflect variation in the divergence dates found in our empirical analysis (see Results). This gave 32 simulation regimes in total, which were all combinations of the four demographic models, presence/absence of IBD, and four time frames.

We selected parameter values for the models based on empirical estimates and suggested practices (Table 1; see Appendix 1). We used ecological niche models (ENMs) to provide the landscape under which all demographic models were simulated. This is coarse-scale resolution, solely to generate a scenario where the area between the deserts is not as suitable as the area within the deserts. To do this we used an ENM of Bell's Vireo (Vireo bellii), a species that is dependent on desert habitats, with known population structure and no evidence of dispersal across the CFB (Klicka, Kus, and Burns, 2016; see Appendix 1). From the simulated genetic data, we calculated 11 summary statistics using the R package 'POPGENOME' (Pfeifer, Wittelsbürger, Ramos-Onsins, and Lercher, 2014; Table S1.2). These include statistics known to 
be correlated with particular aspects of demographic histories (e.g., Tajima's D, Tajima, 1989; haplotype diversity, Stumpf, 2004; see Appendix 1).

\section{Machine learning pipeline}

We performed model selection across demographic regimes by building a neural network using 'SCIKIT-LEARN', a Python module specifically for machine learning (Pedregosa et al., 2011). Model selection was performed so that we could tell whether the demographic model generating the data could be accurately detected. We analyzed each of the time periods together, as well as separately. The inputs were the 11 summary statistics outlined above (see Appendix 1). The network outputs a $3 \times 1$ matrix where each value in the matrix was the predicted population structure, predicted IBD value, and predicted divergence time. To evaluate the model performance we calculated Accuracy, Precision, Recall, and the F-score. Accuracy is the percentage of correctly identified positives. Precision is the number of true positives over the number of positives identified (i.e., true and false positives). Recall is the number of true positives over the number of actual positives (i.e., true positives and false negatives). The F-score is the weighted average of Precision and Recall.

\section{Results}

Biota around CFB shows variability in evolutionary histories

We found 99 published studies comprising 68 taxa (species complexes of 1-6 species) in 39 families and 19 orders (Asterales, Caryophyllales, Cucurbitales, Pinales, Araneae, Coleoptera, Hymenoptera, Orthoptera, Scorpiones, Anura, Squamata, Testudines, Galliformes, Passeriformes, Piciformes, Artiodactyla, Carnivora, Chiroptera, and Rodentia; Table S1.3; see Appendix 2 fordata sources). Phylogeographic inference was performed using a range of data including mitochondrial, chloroplast, and nuclear loci, microsatellites, allozymes, fragment length polymorphisms, and next generation sequencing (e.g., RADseq, UCEs). Some taxa had descriptions of variation across space that were based on phenotypic assessments, but all but one species had genetic data to reinforce those inferences. Seventeen taxa were supported using next-generation sequencing data.

The majority of the taxa $(\sim 62 \%)$ showed evidence for phylogeographic structure across the CFB (Figure S1.1). Of the 68 taxa examined, 41 showed structure (with 38/41 monophyletic), 13 showed no structure, and the remainder had unclear results where it was ambiguous whether there was structure. Divergence times were estimated in 27/41 taxa and ranged from the Miocene to the Pleistocene with no clear temporal congruence across species. Of these, 12/27 were in the Pleistocene alone, with an additional three overlapping the Pleistocene and other epochs. The remaining 18 were not explicitly dated, but for five of those taxa Pleistocene glacial cycles are cited as being a major driver of divergence.

Just under half of the taxa with phylogeographic structure had an estimate of gene flow (Table S1.3, Figure S1.1). Of the 32 taxa, five had no gene flow across the CFB, 13 had gene flow, and the rest had ambiguous results. For the 17 species that were structured and had gene flow estimated, these numbers were three with no gene flow, seven with gene flow, and seven with ambiguous results. Allopatry was the primary mode of speciation proposed, with isolation-by-environment secondary. Some of the studies that found support for gene flow (and thereby isolation-with-migration or secondary contact) concluded that pure allopatric speciation was taking place. Of the 55/68 taxa that had clear or ambiguous splits across the CFB, allopatric 
speciation was the mode of speciation proposed for 19 taxa, with an additional five identifying allopatry with another mode of speciation, including hybrid speciation, polyploidy, and sexual selection (Table S1.3). Another 12/54 declared isolation-by-environment alone (often with the influence of IBD) as the main driver; all these taxa had support from next-generation-sequencing data and were from the same study (Myers et al., 2019). The remaining 19 taxa did not have inferred modes of speciation. There appears to be a temporal bias in the interpretation of these results: only recent papers (2004-2019, median 2017) suggested isolation-by-environment as the main driver, while older papers overwhelmingly suggested allopatry either alone (1986-2018, median 2005) or with another mechanism (1996-2014, median 2005).

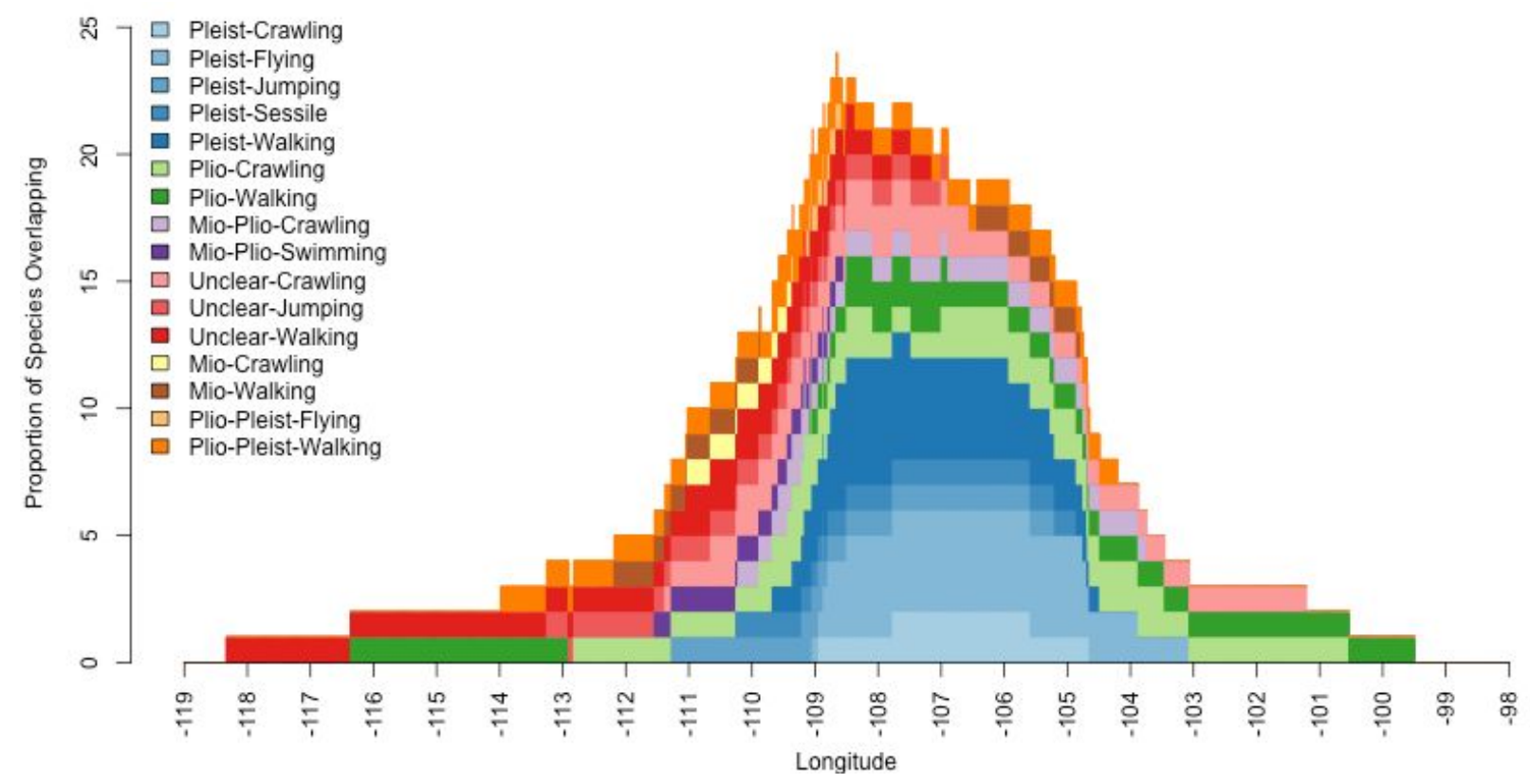

Figure 3: The width of the CFB contact zone for taxa varies by the timing of divergence and the type of locomotion. Colors correspond to unique combinations of divergence and locomotion. Hues represent divergence times (Pleistocene, Pliocene, Miocene, Unclear, etc.) and shades represent locomotion types (Crawling, Flying, Walking, etc.). X-axis shows the longitudinal range, $\mathrm{Y}$-axis shows the number of species that overlap a given longitude. See also Figures S1.2 and S1.3.

The location and width of the contact zone varied between species and also varied with respect to the divergence times and locomotor types (Figure 3; Figure S1.2, Figure S1.3). The total extent of the barrier ranged from $118.3-99.5^{\circ} \mathrm{W}$ longitude, or $18.8^{\circ}$ longitude width. Of the 36 species for which we could estimate where the barrier was, $24 / 36$ overlapped $108.6^{\circ} \mathrm{W}$, the maximum number of species to overlap. The zone of overlap for over $50 \%$ of the taxa (18 or more species) ranged from $109.3-105.6^{\circ} \mathrm{W}$. The contact zone widths for each taxon ranged from $0.3-11.2^{\circ} \mathrm{W}$.

The overall width of the contact zone at the barrier varies with respect to divergence time (Figure S1.2). Width peaks for taxa who diverged in the Pliocene $\left(16.9^{\circ}\right)$, decreasing as divergence dates get both older $\left(7.4-7.7^{\circ}\right)$ and younger $\left(8.2-9.3^{\circ}\right)$. The contact zone width also varies with respect to locomotion type (Figure S1.3; see Appendix 1). Walking taxa span the entire range of $18.8^{\circ}$. For the other locomotion types, the largest to smallest width goes crawling, jumping, flying, sessile, and swimming taxa $\left(12.7-3.0^{\circ}\right)$. In addition, locomotion type and 
structure co-vary (Figure 4). Flying species have the lowest percent of taxa with structure (8/17, $\sim 47 \%)$. All swimming and jumping taxa $(N=1, N=3)$ have structure. Of the rest, walking species have the highest percentage of taxa with structure $(19 / 27, \sim 70 \%)$ followed by crawling $(10 / 16$, $\sim 63 \%$ ) and sessile species $(2 / 4,50 \%)$.

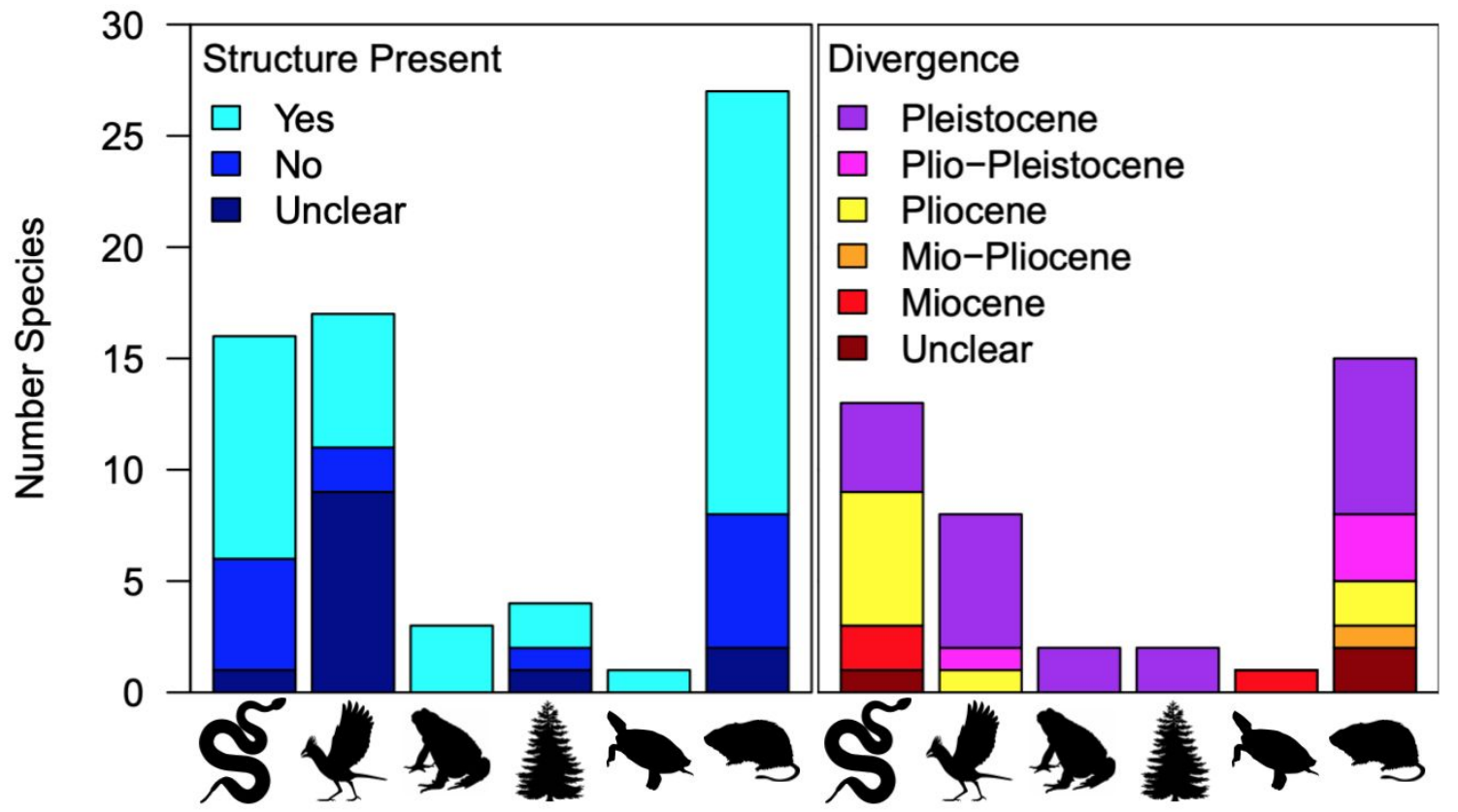

Figure 4: The presence of phylogeographic structure and divergence time across the Cochise Filter Barrier vary based on the locomotion type. X-axis: locomotion type (from left: crawling, flying, jumping, sessile, swimming, walking). Y-axis: number of species per category. Colors describe the presence/absence of phylogeographic structure (left), or the divergence time (right).

The influence of thermoregulation on divergence appears to be less clear than the influence of locomotion (see Appendix 1). A higher proportion of ectotherms are found to have structure $(27 / 40, \sim 68 \%)$ than endotherms $(14 / 28,50 \%)$, but the difference is not significant $\left(\chi^{2}=2.11, \mathrm{p}=0.15\right)$. Ectotherms may also have older divergences: all of the taxa whose divergences overlap the Miocene are ectothermic (Figure S1.4) and of the remaining, proportionately fewer endotherms diverge in the Pliocene $(2 / 9, \sim 22 \%)$ than the Pleistocene $(14 / 27, \sim 52 \%)$. Both thermoregulation and locomotion are significant predictors of divergence date (thermoregulation $\mathrm{R}^{2}=0.14, \mathrm{p}=0.0078$, locomotion $\mathrm{R}^{2}=0.25, \mathrm{p}=0.025$ ), though not when they are both in the same model $\left(\mathrm{R}^{2}=0.31\right.$, thermoregulation $\mathrm{p}=0.060$, locomotion $\left.\mathrm{p}=0.088\right)$. They are still significant when accounting for elevational preference, taxonomy, or both simultaneously (range $\mathrm{R}^{2}=0.14-0.34$, thermoregulation $\mathrm{p}=0.0054-0.014$, locomotion $\mathrm{p}=0.013-0.047$ ). Of the taxa examined, 34 were found in lowlands, 10 were montane, and the remainder were found in both; however, elevational preference is not a significant predictor of divergence time (with and without taxonomy $\mathrm{p}=0.57$ ).

Accuracy of machine learning classification varies with age and phylogeographic history

After calculating summary statistics, removing duplicate simulations that produced the exact same statistics, and eliminating collinear variables, we had 26,131 unique sets of summary statistics. The number of summary statistic sets per model varied based on the number of 
generations each model ran for (6,000 generations: 834-1,099 sets per model; 21,000: 1,011-1,200; 120,000: 1,100-1,100, 1,000,000: 80-100). Generally, younger runs were more likely to produce duplicate results.

Table 1: Model performance. Accuracies are calculated for phylogeographic structure alone (P), IBD alone (I), and ages alone (A) when applicable. "Gens." =generations. "Acc." =accuracy.

\begin{tabular}{|c|c|c|c|c|c|c|c|}
\hline Gens. & Dataset & Precision & Recall & F-score & Acc. (P) & Acc. (I) & Acc. (A) \\
\hline 6,000 & Training & 0.68 & 0.68 & 0.68 & 0.71 & 0.95 & $n / a$ \\
\hline 6,000 & Validation & 0.24 & 0.25 & 0.24 & 0.28 & 0.84 & $n / a$ \\
\hline 6,000 & Test & 0.23 & 0.23 & 0.23 & 0.28 & 0.83 & $n / a$ \\
\hline 21,000 & Training & 0.74 & 0.74 & 0.74 & 0.79 & 0.94 & $n / a$ \\
\hline 21,000 & Validation & 0.30 & 0.30 & 0.30 & 0.35 & 0.86 & $n / a$ \\
\hline 21,000 & Test & 0.32 & 0.33 & 0.32 & 0.37 & 0.87 & $n / a$ \\
\hline 120,000 & Training & 0.83 & 0.83 & 0.83 & 0.85 & 0.97 & $n / a$ \\
\hline 120,000 & Validation & 0.42 & 0.42 & 0.42 & 0.47 & 0.88 & $n / a$ \\
\hline 120,000 & Test & 0.39 & 0.39 & 0.39 & 0.47 & 0.86 & $n / a$ \\
\hline $1,000,000$ & Training & 0.74 & 0.73 & 0.72 & 0.76 & 0.95 & $n / a$ \\
\hline $1,000,000$ & Validation & 0.57 & 0.55 & 0.52 & 0.62 & 0.88 & $n / a$ \\
\hline $1,000,000$ & Test & 0.65 & 0.65 & 0.64 & 0.72 & 0.87 & $n / a$ \\
\hline All & Training & 0.49 & 0.48 & 0.48 & 0.60 & 0.92 & 0.83 \\
\hline All & Validation & 0.23 & 0.23 & 0.22 & 0.39 & 0.85 & 0.68 \\
\hline All & Test & 0.24 & 0.24 & 0.23 & 0.40 & 0.86 & 0.67 \\
\hline
\end{tabular}

The neural network varied in accuracy (Table 1, Table S1.4), but was consistently good at classifying whether models had IBD, less good (but consistent) at classifying the number of generations after divergence, and inconsistent at classifying the true demographic model. When the network was asked to classify if IBD was present, it did so with high accuracy regardless of how many generations after divergence or how many summary statistics were used $(92-100 \%$ for training, 81-89\% for validation/testing), and overfitting appeared to be slight (Table 1, Table S1.4; Figure S1.5). Similarly, when the network classified the number of generations since divergence, it did so with $83-85 \%$ accuracy in training, depending on how many summary statistics were used, and $66-68 \%$ in validation/testing. When models were misclassified, it was always to a similar number of generations (e.g., 21,000 generation runs were confused with 6,000 and 120,000 generation runs, but never 1,000,000 generation runs; Figure S1.5). The differences in training and validation/testing suggest slight overfitting. Finally, neural network accuracy for classifying phylogeographic models was much more variable with a lot of overfitting (61-94\% training, 28-62\% validation/testing). Accuracy was positively associated with the number of generations after divergence models were run for, with those that ran for longer having higher ability to differentiate between models (Table 1, Table S1.4).

When examining performance across models (Figure 5), IBD had similar misclassification rates irrespective of the number of generations since divergence and phylogeographic structure simulated. The exception is for models run for 1,000,000 generations after divergence. Here, the single population with IBD models had high (worse than random) misclassification rates. Otherwise, models run for 6,000-120,000 generations tend to have higher misclassification rates, though the trend is reversed for secondary contact models, which have lower misclassification rates. Phylogeographic structure was also more highly misclassified in models with a short number of generations since divergence, irrespective of IBD. Multiple 
models are classified worse than randomly based on age: single population with IBD models (1,000,000 generations), isolation with IBD models (6,000 generations), and isolation-with-migration both with (21,000 generations) and without IBD $(6,000$ generations, 21,000 generations).
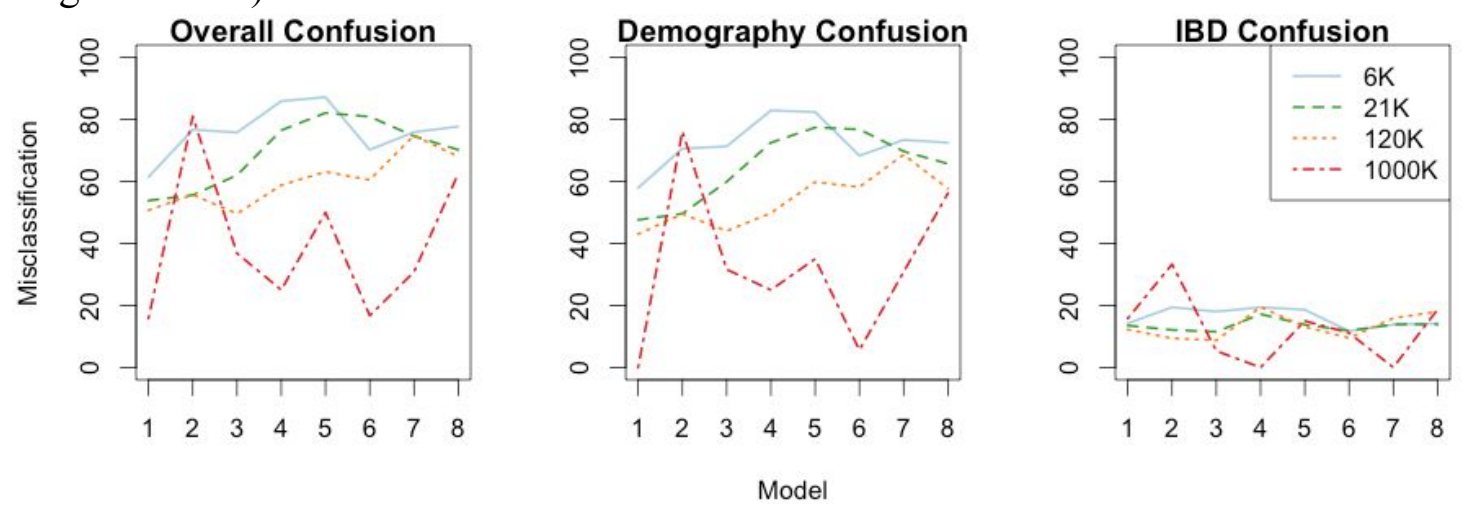

Figure 5: Neural networks classify models with older divergences much better than models with younger divergences. Misclassification rates are given for overall models, phylogeographic models only, and IBD models only. Model numbers on the $\mathrm{x}$-axis correspond to models in Figure 2. Y-axis indicates misclassification rate, with higher values indicating poorer model performance. Lines of different colors and dash types indicate the generations simulated, from $6,000(6 \mathrm{~K})$ to $1,000,000(1000 \mathrm{~K})$ generations.

We examined which misclassifications were most common with respect to the number of generations modeled since divergence (Figure 6, Figure S1.6). From a phylogeographic structure perspective (irrespective of IBD), across all ages of divergence, single population models were likely to be misclassified as isolation-with-migration models and vice versa. Likewise, isolation models were likely to be misclassified as secondary contact models and vice versa. In models that were run for 1,000,000 generations since divergence, misclassifications between isolation/secondary contact and isolation-with-migration/single population were the only misclassifications that occured. However, as the number of generations since divergence decreased, more kinds of misclassifications arose. In models run for 120,000 generations after divergence, isolation-with-migration and secondary contact were misclassified, as were single population and secondary contact. All models were confusable in younger divergences, with confusion greatest in models run 6,000 years after divergence. This reveals that even in lineages with old divergences, single population and isolation-with-migration models are hard to tell apart, as are isolation and secondary contact models. However, the younger a divergence is, and the less time for genetic differences to accumulate, the easier it is to confuse all types of phylogeographic models. When considering misclassifications simultaneously between IBD and phylogeographic structure models, in older models we generally find that when models are misclassified between having IBD and not having IBD, it tends to be within the same model type (i.e., isolation-with-migration with IBD to isolation-with-migration without IBD) or between those models that were already identified as similar when not considering IBD (i.e., secondary contact with IBD to isolation without IBD). However, as models become younger, misclassification becomes more severe. 


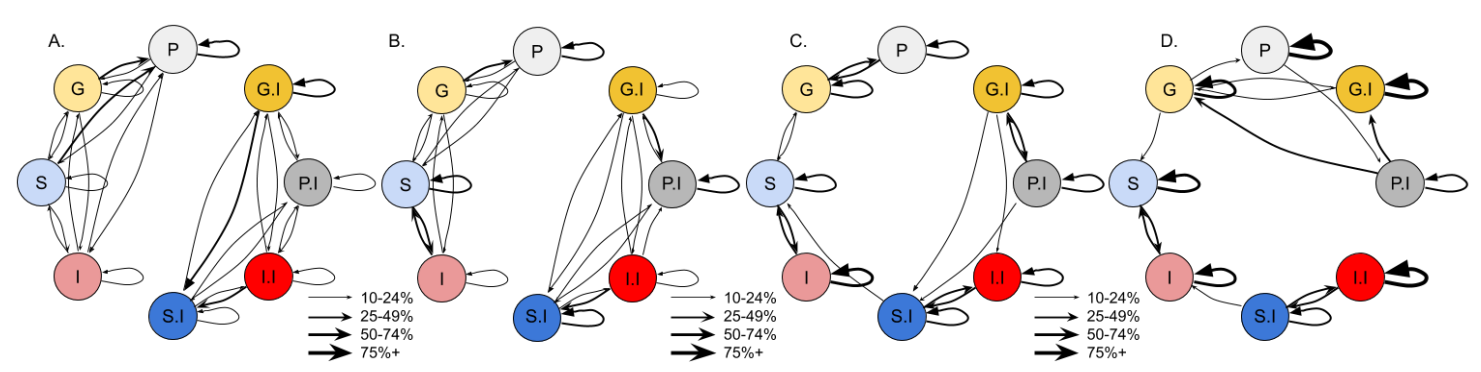

Figure 6: Overall model classifications are easily confused at young ages but improve with older ages. Arrows begin at the true model and end at the assigned model. Line thickness of arrows indicates the percentage of time those assignments are made. Assignments under 10\% are omitted for clarity. Demographics include single panmictic populations ("P", grey), isolation-with-migration or gene flow ("G", yellow), secondary contact ("S", blue), and isolation ("I", red). Suffix of ".I" after demography indicates that IBD is present. A) 6,000 generations. B) 21,000 generations. C) 120,000 generations. D) 1,000,000 generations. Models with IBD are on the right, models without IBD are on the left.

\section{Discussion}

Moving beyond descriptive narratives of landscape change generating biodiversity and understanding how taxa interact with barriers represent major challenges of biogeographic research. We used the Sonoarn and Chihuahuan Deserts as an exemplar system for characterizing genetic differentiation among two regions, quantifying the temporal and spatial dynamics in phylogeographic structuring associated with a filter barrier. The range in divergence times and phylogeographic break locations in taxa distributed across the deserts reflects the semipermeability of the CFB. The variability of molecular data used in this synthesis was not suitable for a formal test of simultaneous divergence (e.g., Hickerson et al., 2006), but the wide disparity of divergence times suggests taxa have been diverging across the CFB for millions of years. Locomotive and thermoregulatory traits help to explain this variation, suggesting that organisms that are more vagile and less dependent on external temperatures (i.e., endotherms) may be better at evading the impacts of the barrier, and selective pressures both on movement and on environmental tolerances might determine which taxa diverge. Divergence in allopatry was typically invoked as the main mode of differentiation across the CFB, but we found evidence of all other processes (i.e., ecological divergence, polyploidy, hybrid speciation, and sexual selection). Fully understanding which filters make up the CFB necessitates a deeper understanding of the mechanisms causing differentiation in the region. Using simulations and model selection approaches can illuminate those mechanisms via rigorous hypothesis testing and replication. These methods offer promise by more accurately identifying modes of differentiation, but the modeled scenarios can be difficult to distinguish. Nevertheless, simulation methods contextualize empirical results and show the utility of genomic-scale data in uncovering phylogeographic histories, allowing us to understand how organisms might be expected to diversify under different known conditions.

\section{The community around barriers are influenced by a multitude of forces}

Biogeographic barriers are typically viewed as abrupt transitions between two biotas, but our analysis showed the conditions in which this view does not hold. The entities identified as biogeographic barriers may represent a combination of forces that generated the contemporary distributions of taxa, which have a wide longitudinal range of phylogeographic breaks across the 
CFB after accounting for uncertainty. Most species have ranges that overlap $109-106$, a shift eastward from the $112-108$ that was conventional in the literature (though very few species do not overlap the original distribution). First, barriers can be ephemeral over time, for example, due to river capture events (Tagliacollo, Roxo, Duke-Sylvester, Oliveira, and Albert, 2015), sea-level changes (Elias, Short, Nelson, and Birks, 1996), or major climatic shifts (possibly including the CFB; Holmgren et al., 2007). Additionally, organisms have the capacity to disperse, which can retain or reintroduce gene flow and connectivity across barriers (Brandley, Guiher, Pyron, Winne, and Burbrink, 2010). Population genetics theory also predicts that even in the absence of a barrier, phylogeographic structure can arise due to simple density troughs, where abundances are low and dispersal out of these troughs fails (Barton and Hewitt, 1981; Barrowclough et al., 2005). Finally, incomplete sampling may be a culprit for the observed differences between taxa, as contact zone widths cannot be estimated without examining specimens. For the CFB, numerous studies lack individuals from the transition zone. Fortunately, targeted sampling of this region will resolve this discrepancy, especially with the addition of genome-level genetic sampling. In our analyses here, we used all individuals to calculate summary statistics, but future work could subset individuals and create incomplete sampling to test for bias.

\section{Locomotion and thermoregulation as filters}

Our results show the expected relationship between locomotion type and how organisms respond to the barrier. We found that flying organisms are less likely to have diverged across the barrier. Flying organisms can have higher dispersal ability than non-flying ones, allowing them to potentially bypass any filtering mechanisms of a biogeographic filter barrier, and previous work has shown that flying organisms tend to show less genetic differentiation than others (Medina, Cooke, and Ord, 2018). The contact zone at the barrier also has a smaller estimated width for flying taxa than those with other forms of locomotion. Under an assumption where flying confers higher dispersal, it is counterintuitive that they should show a narrow range for the CFB, unless dispersal is unable to counteract the strength of the filters operating, but the degree of environmental changes may be relatively stronger than the effects of organismal traits. Flying organisms have a higher proportion of Pleistocene divergences relative to other epochs even after accounting for elevation, which has been found across other biogeographic barriers (e.g., Bacon et al., 2015). It is unclear whether the Pleistocene climatic shifts themselves caused diversification or if some other process produced a suite of divergences that happen to date to the Pleistocene for other reasons. Alternatively, flying species may have more suitable habitat available to them across the barrier relative to other taxa, which would weaken the impact of the CFB. This would explain both the shallow divergences and the narrow width. In addition, some taxa are clearly undersampled (e.g., sessile plants) or less abundant in desert habitats (e.g., swimming fish), though for other taxa it is less clear. Increasing sampling of organisms with these forms of dispersal would clarify the causes of these trends.

Ectothermic taxa appear more likely to diversify across the CFB than endothermic taxa, though the patterns are not significant. As ectothermic organisms are more reliant on external temperature regulation than endotherms (particularly microhabitat selection; Boyko, 2014), it is feasible that any environmental changes should disproportionately affect them. Under such an assumption, the climatic dynamism of the Pleistocene would have been a stronger filter on ectotherms, though it would not explain the ectothermic taxa that diverged in the Pliocene. 
Alternatively, local adaptation could be a stronger process in ectotherms relative to endotherms, which would explain divergence under an ecological-speciation hypothesis (Nosil, 2012).

The traits we chose to use in this study were simple to quantify across all of these taxa. Many more traits may be involved in mediating which species diverge across this and other barriers. For example, habitat preferences could be driving the pattern in addition to or instead of the ones we have identified here. The relative width of the contact zone for a taxon could be changed as the traits interact with the properties of the barrier, for example, whether it allows frequent or infrequent dispersal (see Pyron and Burbrink, 2010), is long-lived or ephemeral, and/or relocates through time. Further, both of these traits are presumably the result of selection, whereas more stochastic forces could be at play. Overall, phenotypic traits could be important for determining why multiple co-distributed taxa are concordant or discordant with respect to their phylogeographic histories (Zamudio, Bell, and Mason, 2016).

One major limitation of this study is that it does not assess any taxa that completely fail to get through the barrier, i.e., taxa that are restricted to one side. There are numerous examples of single-desert endemics in the region, one of the most famous being that of the saguaro cactus (Carnegiea gigantea) of the Sonoran desert. Understanding which organisms fall into that category would greatly improve knowledge of what factors make the CFB a potent barrier. A difficulty in such an assessment would be identifying which organisms have successfully crossed but one population was extirpated by chance vs. organisms that never crossed successfully. Still, the taxa that are unable to get past the barrier would give insight into exactly what filters are operating through analyses of their traits and the properties of the barrier.

\section{Genome-level data can clarify phylogeographic patterns}

Ultimately, even in aggregate, the studies performed on the CFB do not provide enough information to explain the mechanisms of diversification in the region. Using machine learning methods on large simulated datasets, combined with empirical and theoretical studies, allows for testing between phylogeographic models with numerous parameters of interest; for example, the divergence mechanisms in Australian honeyeaters are ambiguous in empirical data but may be resolvable using a simulated approach (Toon, Hughes, Joseph, 2020). Our simulations here are only a subset of model parameter space and larger genomic regions, population growth, and selection could be considered (Carstens et al., 2013; Ewing and Jensen, 2016). Likewise, we do not account for changes in parameter space over time (e.g., population size, mutation rate, environmental factors). Demographic expansions and contractions in effective population size cause changes in the impact of genetic drift, and there are numerous examples of phylogeographic studies that find these changes in concordance with genetic structure (e.g., Smith et al., 2011; Charruau et al., 2012). Changes in habitat suitability over time can lead to similar changes; fortunately, spatially explicit methods can incorporate these changes via the addition of paleoclimate models, some of which go back to the Pliocene (e.g., PRISM4; Dowsett et al., 2016).

The machine learning method we used here, neural networks, allow for direct estimation of the model power and model identifiability in test data, which can be leveraged when analyzing both simulated and empirical datasets. Validation schemes indicate how well a model performs on known models, giving estimates of error and describing which models have problems with identifiability. Here, the identifiability of our models was high when classifying IBD and generation times. However, it is notable that at very young divergence times, our method still 
struggled to tell apart different models, which may imply that differences between isolation and secondary-contact models are inscrutable without longer divergence histories. The difficulty in identifying models is well known when analyzing certain data types, the SFS in particular: population size is hard to estimate, especially when it has been dynamic over time (Lapierre, Lambert, and Achaz, 2017; Terhorst and Song, 2015), and the presence of ancient population structure can erroneously appear as though gene flow has occurred (Eriksson and Manica, 2014). If these tenets also hold for additional summary statistics, they must be accounted for in future work. Nevertheless, this all serves to reinforce that biologically similar models tend to be confused with one another (e.g., Roux et al., 2016). Further work will require more rigorous testing as to the impact of model selection on different biological scenarios.

In conclusion, we synthesized phylogeographic studies across an exemplar barrier, examining how biogeographic filters affect the community. Among all species, gene flow, phylogeographic structuring, and timing of divergence all varied substantially. The location of the barrier and width of the contact zone are related to locomotion and thermoregulation, irrespective of phylogeny and elevational preferences. Simulations and machine learning allowed us to quantify spatiotemporal evolutionary histories, finding numerous aspects of demography including gene flow and isolation-by-distance are major confounding variables. Overall, barriers interact with traits of species to cause heterogeneous differentiation, but identifying the exact causes remains challenging.

\section{Acknowledgements}

We are grateful to all the authors whose work supported our synthesis. KLP was supported by Frank M. Chapman, Sydney Anderson, and Linda H. Gormezano funds, AOS, SSB, and RGGS. Computational resources provided by the Open Science Grid (Pordes et al., 2007, Sfiligoi et al., 2009; NSF award 1148698 and the U.S. DoE's Office of Science). EAM was supported through the Peter Buck and Rathbone Bacon Fellowship from the National Museum of Natural History. We thank F. Burbrink for the photographs. Feedback comes from M. Blair, L. Alter, C. Raxworthy, J. Padial, E. Rodriguez, L. Musher, L. Moreira, J. Merwin, G. Thom, G. Seeholzer, V. Chua, J. Denton, D. Kelly, I. Overcast, A. Xue, M. Ingala, M. Hickerson, M. Gehara, and B. Haller.

\section{References}

Avise, J. C., Arnold, J., Ball, R. M., Bermingham, E., Lamb, T., Neigel, J. E. ... Saunders, N. C. (1987). Intraspecific phylogeography: the mitochondrial DNA bridge between population genetics and systematics. Annual Review of Ecology and Systematics, 18(1), 489-522.

Avise, J. C., Bowen, B. W., \& Ayala, F. J. (2016). In the light of evolution X: Comparative phylogeography. Proceedings of the National Academy of Sciences, 113(29), 7957-7961.

Bacon, C. D., Silvestro, D., Jaramillo, C., Smith, B. T., Chakrabarty, P., \& Antonelli, A. (2015). Biological evidence supports an early and complex emergence of the Isthmus of Panama. Proceedings of the National Academy of Sciences, 112(19), 6110-6115.

Barrowclough, G. F., Groth, J. G., Mertz, L. A., \& Gutierrez, R. J. (2005). Genetic structure, introgression, and a narrow hybrid zone between northern and California spotted owls (Strix occidentalis). Molecular Ecology, 14(4), 1109-1120. 
Barton, N. H., \& Hewitt, G. M. (1981). Hybrid zones and speciation. In W. R. Atchley \& D. S. Woodruff (Eds.), Evolution and Speciation: Essays in honour of M. J. D White (pp. 109-145). Cambridge, UK: Cambridge University Press.

Bates, D., Mächler, M., Bolker, B., \& Walker, S. (2014). Fitting linear mixed-effects models using lme4. arXiv, 1406.5823.

Battey, C. J., Ralph, P. L., \& Kern, A. D. (2020). Space is the place: Effects of continuous spatial structure on analysis of population genetic data. Genetics, 215(1), 193-214.

Bierne, N., Gagnaire, P. A., \& David, P. (2013). The geography of introgression in a patchy environment and the thorn in the side of ecological speciation. Current Zoology, 59(1), 72-86.

Boyko, H. (2014). The biological significance of the microclimate for plants and animals. In P. H. Stoutjesdijk \& J. J. Barkman (Eds.), Microclimate, Vegetation \& Gauna (pp. 133-169). Leiden: Brill.

Bradburd, G. S., Coop, G. M., \& Ralph, P. L. (2018). Inferring continuous and discrete population genetic structure across space. Genetics, 210(1), 33-52.

Brandley, M. C., Guiher, T. J., Pyron, R. A., Winne, C. T., \& Burbrink, F. T. (2010). Does dispersal across an aquatic geographic barrier obscure phylogeographic structure in the diamond-backed watersnake (Nerodia rhombifer)? Molecular Phylogenetics and Evolution, 57(2), 552-560.

Burbrink, F. T., Chan, Y. L., Myers, E. A., Ruane, S., Smith, B. T., \& Hickerson, M. J. (2016). Asynchronous demographic responses to Pleistocene climate change in Eastern Nearctic vertebrates. Ecology Letters, 19(12), 1457-1467.

Carnicer, J., Brotons, L., Stefanescu, C., \& Penuelas, J. (2012). Biogeography of species richness gradients: linking adaptive traits, demography and diversification. Biological Reviews, 87(2), 457-479.

Carstens, B. C., Brennan, R. S., Chua, V., Duffie, C. V., Harvey, M. G., Koch, R. A., ... Seeholzer, G. (2013). Model selection as a tool for phylogeographic inference: an example from the willow Salix melanopsis. Molecular Ecology, 22(15), 4014-4028.

Castoe, T. A., Spencer, C. L., \& Parkinson, C. L. (2007). Phylogeographic structure and historical demography of the western diamondback rattlesnake (Crotalus atrox): a perspective on North American desert biogeography. Molecular Phylogenetics and Evolution, 42(1), 193-212.

Charruau, P., Fernandes, C., Orozco-terWengel, P., Peters, J., Hunter, L., Ziaie, H., ... Burger, P. A. (2011). Phylogeography, genetic structure and population divergence time of cheetahs in Africa and Asia: evidence for long-term geographic isolates. Molecular Ecology, 20(4), 706-724.

Christe, C., Stölting, K. N., Bresadola, L., Fussi, B., Heinze, B., Wegmann, D., \& Lexer, C. (2016). Selection against recombinant hybrids maintains reproductive isolation in hybridizing Populus species despite F1 fertility and recurrent gene flow. Molecular Ecology, 25(11), 2482-2498.

Cruickshank, T. E., \& Hahn, M. W. (2014). Reanalysis suggests that genomic islands of speciation are due to reduced diversity, not reduced gene flow. Molecular Ecology, 23(13), 3133-3157. 
Currat, M., Arenas, M., Quilodràn, C. S., Excoffier, L., \& Ray, N. (2019). SPLATCHE3: simulation of serial genetic data under spatially explicit evolutionary scenarios including long-distance dispersal. Bioinformatics, 35(21), 4480-4483.

de Queiroz, K. (2005). A unified concept of species and its consequences for the future of taxonomy. Proceedings of the California Academy of Sciences.

Dick, C. W., Hardy, O. J., Jones, F. A., \& Petit, R. J. (2008). Spatial scales of pollen and seed-mediated gene flow in tropical rain forest trees. Tropical Plant Biology, 1(1), 20-33.

Dowsett, H., Dolan, A., Rowley, D., Pound, M., Salzmann, U., Robinson, M., ... Haywood, A. (2016). The PRISM4 (mid-Piacenzian) palaeoenvironmental reconstruction. Climate of the Past Discussions, 12, 1519-1538.

Eckert, A. J., \& Carstens, B. C. (2008). Does gene flow destroy phylogenetic signal? The performance of three methods for estimating species phylogenies in the presence of gene flow. Molecular Phylogenetics and Evolution, 49(3), 832-842.

Edwards, M. E., Lloyd, A., \& Armbruster, W. S. (2018). Assembly of Alaska-Yukon boreal steppe communities: Testing biogeographic hypotheses via modern ecological distributions. Journal of Systematics and Evolution, 56(5), 466-475.

Elias, S. A., Short, S. K., Nelson, C. H., \& Birks, H. H. (1996). Life and times of the Bering land bridge. Nature, 382(6586), 60-63.

Eriksson, A., \& Manica, A. (2014). The doubly conditioned frequency spectrum does not distinguish between ancient population structure and hybridization. Molecular Biology and Evolution, 31(6), 1618-1621.

Ewing, G. B., \& Jensen, J. D. (2016). The consequences of not accounting for background selection in demographic inference. Molecular Ecology, 25(1), 135-141.

Fouquet, A., Green, D. M., Waldman, B., Bowsher, J. H., McBride, K. P., \& Gemmell, N. J. (2010). Phylogeography of Leiopelma hochstetteri reveals strong genetic structure and suggests new conservation priorities. Conservation Genetics, 11(3), 907-919.

Garrick, R. C., Bonatelli, I. A., Hyseni, C., Morales, A., Pelletier, T. A., Perez, M. F., ... Carstens, B. C. (2015). The evolution of phylogeographic data sets. Molecular Ecology, 24(6), 1164-1171.

Gravel, S. (2012). Population genetics models of local ancestry. Genetics, 191(2), 607-619.

Gutenkunst, R. N., Hernandez, R. D., Williamson, S. H., \& Bustamante, C. D. (2009). Inferring the joint demographic history of multiple populations from multidimensional SNP frequency data. PLoS Genetics, 5(10).

Hafner, D. J., \& Riddle, B. R. (2011). Boundaries and barriers of North American warm deserts: an evolutionary perspective. In P. Upchurch, A. J. McGowan, C. S. C. Slater (Eds.) Palaeogeography and palaeobiogeography: biodiversity in space and time (pp. 75-114). Boca Raton, FL: CRC Press.

Haller, B. C., \& Messer, P. W. (2019a). SLiM 3: forward genetic simulations beyond the Wright-Fisher model. Molecular Biology and Evolution, 36(3), 632-637.

Haller, B. C., Galloway, J., Kelleher, J., Messer, P. W., \& Ralph, P. L. (2019). Tree-sequence recording in SLiM opens new horizons for forward-time simulation of whole genomes. Molecular Ecology Resources, 19(2), 552-566.

Hanson, C. A., Fuhrman, J. A., Horner-Devine, M. C., \& Martiny, J. B. (2012). Beyond biogeographic patterns: processes shaping the microbial landscape. Nature Reviews Microbiology, 10(7), 497-506. 
Helbig, A. J., Knox, A. G., Parkin, D. T., Sangster, G., \& Collinson, M. (2002). Guidelines for assigning species rank. Ibis, 144(3), 518-525.

Hickerson, M. J., Carstens, B. C., Cavender-Bares, J., Crandall, K. A., Graham, C. H., Johnson, J. B., ... Yoder, A. D. (2010). Phylogeography's past, present, and future: 10 years after. Molecular Phylogenetics and Evolution, 54(1), 291-301.

Hickerson, M. J., Stahl, E. A., \& Lessios, H. A. (2006). Test for simultaneous divergence using approximate Bayesian computation. Evolution, 60(12), 2435-2453.

Hickerson, M. J., Stahl, E., \& Takebayashi, N. (2007). msBayes: pipeline for testing comparative phylogeographic histories using hierarchical approximate Bayesian computation. $B M C$ Bioinformatics, 8(1), 268.

Holmgren, C. A., Norris, J., \& Betancourt, J. L. (2007). Inferences about winter temperatures and summer rains from the late Quaternary record of $\mathrm{C} 4$ perennial grasses and $\mathrm{C} 3 \mathrm{desert}$ shrubs in the northern Chihuahuan Desert. Journal of Quaternary Science: Published for the Quaternary Research Association, 22(2), 141-161.

Hoskin, C. J., Higgie, M., McDonald, K. R., \& Moritz, C. (2005). Reinforcement drives rapid allopatric speciation. Nature, 437(7063), 1353.

Jackson, N. D., Morales, A. E., Carstens, B. C., \& O’Meara, B. C. (2017). PHRAPL:

Phylogeographic inference using approximate likelihoods. Systematic Biology, 66(6), 1045-1053.

Janzen, D. H. (1967). Why mountain passes are higher in the tropics. The American Naturalist, 101(919), 233-249.

Klicka, L. B., Kus, B. E., \& Burns, K. J. (2016). Conservation genomics reveals multiple evolutionary units within Bell's Vireo (Vireo bellii). Conservation Genetics, 17(2), 455-471.

Kozak, K. H., Blaine, R. A., \& Larson, A. (2006). Gene lineages and eastern North American palaeodrainage basins: phylogeography and speciation in salamanders of the Eurycea bislineata species complex. Molecular Ecology, 15(1), 191-207.

Lapierre, M., Lambert, A., \& Achaz, G. (2017). Accuracy of demographic inferences from the site frequency spectrum: the case of the Yoruba population. Genetics, 206(1), 439-449.

Lomolino, M. V., Sax, D. F., \& Brown, J. H. (Eds.). (2004). Foundations of biogeography: classic papers with commentaries. Chicago, IL: University of Chicago Press.

MacArthur, R. H., \& Wilson, E. O. (1967). Island biogeography. Princeton.

Matos, M. V., Borges, S. H., d'Horta, F. M., Cornelius, C., Latrubesse, E., Cohn-Haft, M., \& Ribas, C. C. (2016). Comparative phylogeography of two bird species, Tachyphonus phoenicius (Thraupidae) and Polytmus theresiae (Trochilidae), specialized in Amazonian white-sand vegetation. Biotropica, 48(1), 110-120.

Mayr, E. (1942). Systematics and the origin of species, from the viewpoint of a zoologist. Cambridge, MA: Harvard University Press.

Medina, I., Cooke, G. M., \& Ord, T. J. (2018). Walk, swim or fly? Locomotor mode predicts genetic differentiation in vertebrates. Ecology Letters, 21(5), 638-645.

Meirmans, P. G. (2012). The trouble with isolation by distance. Molecular Ecology, 21(12), 2839-2846.

Myers, E. A., Hickerson, M. J., \& Burbrink, F. T. (2017). Asynchronous diversification of snakes in the North American warm deserts. Journal of Biogeography, 44(2), 461-474. 
Myers, E. A., Xue, A. T., Gehara, M., Cox, C. L., Davis Rabosky, A. R., Lemos-Espinal, J., ... Burbrink, F. T. (2019). Environmental heterogeneity and not vicariant biogeographic barriers generate community-wide population structure in desert-adapted snakes. Molecular Ecology, 28(20), 4535-4548.

Nosil, P. (2008). Speciation with gene flow could be common. Molecular Ecology, 17(9), 2103-2106.

Nosil, P. (2012). Ecological speciation. Oxford, UK: Oxford University Press.

Olson, D. M., Dinerstein, E., Wikramanayake, E. D., Burgess, N. D., Powell, G. V., Underwood, E. C., ... Loucks, C. J. (2001). Terrestrial Ecoregions of the World: A New Map of Life on EarthA new global map of terrestrial ecoregions provides an innovative tool for conserving biodiversity. BioScience, 51(11), 933-938.

Overcast, I., Emerson, B. C., \& Hickerson, M. J. (2019). An integrated model of population genetics and community ecology. Journal of Biogeography, 46(4), 816-829.

Pedregosa, F., Varoquaux, G., Gramfort, A., Michel, V., Thirion, B., Grisel, O., ... Vanderplas, J. (2011). Scikit-learn: Machine learning in Python. Journal of Machine Learning Research, 12, 2825-2830.

Pfeifer, B., Wittelsbürger, U., Ramos-Onsins, S. E., \& Lercher, M. J. (2014). PopGenome: an efficient Swiss army knife for population genomic analyses in R. Molecular Biology and Evolution, 31(7), 1929-1936.

Pordes, R., Petravick, D., Kramer, B., Olson, D., Livny, M., Roy, A., ... Foster, I. (2007). The open science grid. In Journal of Physics: Conference Series, 78 (1), 012057.

Provost, K. L., Mauck III, W. M., \& Smith, B. T. (2018). Genomic divergence in allopatric Northern Cardinals of the North American warm deserts is linked to behavioral differentiation. Ecology and Evolution, 8(24), 12456-12478.

Pyron, R. A., \& Burbrink, F. T. (2010). Hard and soft allopatry: physically and ecologically mediated modes of geographic speciation. Journal of Biogeography, 37(10), 2005-2015.

Remington, C. L. (1968). Suture-zones of hybrid interaction between recently joined biotas. In Evolutionary Biology (pp. 321-428). Springer, Boston, MA.

Reynolds, J. F., Kemp, P. R., Ogle, K., \& Fernández, R. J. (2004). Modifying the 'pulse-reserve' paradigm for deserts of North America: precipitation pulses, soil water, and plant responses. Oecologia, 141(2), 194-210.

Riddle, B. R., \& Hafner, D. J. (2006). A step-wise approach to integrating phylogeographic and phylogenetic biogeographic perspectives on the history of a core North American warm deserts biota. Journal of Arid Environments, 66(3), 435-461.

Ripley, B. D. (1996). Pattern recognition and neural networks. Cambridge University Press, Cambridge.

Roux, C., Fraisse, C., Romiguier, J., Anciaux, Y., Galtier, N., \& Bierne, N. (2016). Shedding light on the grey zone of speciation along a continuum of genomic divergence. PLoS Biology, 14(12), e2000234.

Satler, J. D., \& Carstens, B. C. (2017). Do ecological communities disperse across biogeographic barriers as a unit? Molecular Ecology, 26(13), 3533-3545.

Schrider, D. R., \& Kern, A. D. (2018). Supervised machine learning for population genetics: a new paradigm. Trends in Genetics, 34(4), 301-312. 
Sfiligoi, I., Bradley, D. C., Holzman, B., Mhashilkar, P., Padhi, S., \& Wurthwein, F. (2009). The pilot way to grid resources using glideinWMS. In 2009 WRI World congress on computer science and information engineering, 2, 428-432.

Shreve, F. (1942). The desert vegetation of North America. Botanical Review, 8(4), 195-246.

Simpson, G. G. (1940). Mammals and land bridges. Journal of the Washington Academy of Sciences, 30(4), 137-163.

Smith, B. T., Escalante, P., Baños, B. E. H., Navarro-Sigüenza, A. G., Rohwer, S., \& Klicka, J. (2011). The role of historical and contemporary processes on phylogeographic structure and genetic diversity in the Northern Cardinal, Cardinalis cardinalis. BMC Evolutionary Biology, 11(1), 136.

Spencer, J. E. (1996). Uplift of the Colorado Plateau due to lithosphere attenuation during Laramide low-angle subduction. Journal of Geophysical Research: Solid Earth, 101(B6), 13595-13609.

Stumpf, M. P. (2004). Haplotype diversity and SNP frequency dependence in the description of genetic variation. European Journal of Human Genetics, 12(6), 469-477.

Swenson, N. G., \& Howard, D. J. (2005). Clustering of contact zones, hybrid zones, and phylogeographic breaks in North America. The American Naturalist, 166(5), 581-591.

Taberlet, P., \& Bouvet, J. (1994). Mitochondrial DNA polymorphism, phylogeography, and conservation genetics of the brown bear Ursus arctos in Europe. Proceedings of the Royal Society of London. Series B: Biological Sciences, 255(1344), 195-200.

Tagliacollo, V. A., Roxo, F. F., Duke-Sylvester, S. M., Oliveira, C., \& Albert, J. S. (2015). Biogeographical signature of river capture events in Amazonian lowlands. Journal of Biogeography, 42(12), 2349-2362.

Tajima, F. (1989). Statistical method for testing the neutral mutation hypothesis by DNA polymorphism. Genetics, 123(3), 585-595.

Terhorst, J., \& Song, Y. S. (2015). Fundamental limits on the accuracy of demographic inference based on the sample frequency spectrum. Proceedings of the National Academy of Sciences, 112(25), 7677-7682.

Thompson, R. S., \& Anderson, K. H. (2000). Biomes of western North America at 18,000, 6000 and $014 \mathrm{C}$ yr BP reconstructed from pollen and packrat midden data. Journal of Biogeography, 27(3), 555-584.

Toon, A., Hughes, J. M., \& Joseph, L. (2010). Multilocus analysis of honeyeaters (Aves: Meliphagidae) highlights spatio-temporal heterogeneity in the influence of biogeographic barriers in the Australian monsoonal zone. Molecular Ecology, 19(14), 2980-2994.

Van Devender, T. R. (1990). Late quaternary vegetation and climate of the Sonoran Desert, United States and Mexico. In J. L.Betancourt, T. R. Van Devender, P. S. Martin (Eds.) Packrat middens: the last 40,000 Years of Biotic Change (pp. 134-165). Tucson, AZ: University of Arizona Press.

Wilson, J. S., \& Pitts, J. P. (2010). Phylogeographic analysis of the nocturnal velvet ant genus Dilophotopsis (Hymenoptera: Mutillidae) provides insights into diversification in the Nearctic deserts. Biological Journal of the Linnean Society, 101(2), 360-375.

Wright, S. (1943). Isolation by distance. Genetics, 28(2), 114.

Xue, A. T., \& Hickerson, M. J. (2017). multi-dice: r package for comparative population genomic inference under hierarchical co-demographic models of independent single-population size changes. Molecular Ecology Resources, 17(6), e212-e224. 
Zamudio, K. R., Bell, R. C., \& Mason, N. A. (2016). Phenotypes in phylogeography: Species’ traits, environmental variation, and vertebrate diversification. Proceedings of the National Academy of Sciences, 113(29), 8041-8048.

Zhang, R., Song, G., Qu, Y., Alström, P., Ramos, R., Xing, X., ... Kristin, A. (2012). Comparative phylogeography of two widespread magpies: importance of habitat preference and breeding behavior on genetic structure in China. Molecular Phylogenetics and Evolution, 65(2), 562-572.

Zink, R. M., Kessen, A. E., Line, T. V., \& Blackwell-Rago, R. C. (2001). Comparative phylogeography of some aridland bird species. The Condor, 103(1), 1-10. 


\section{Appendix 1: Supplementary Analyses and Results}

We classified taxa into categories based on published elevational ranges: desert lowland, highland montane, or both. We then performed GLMM to predict divergence times based on combinations of 1-3 organismal traits (locomotive, thermoregulatory, elevational), and one of six classification groups (i.e., Genus through Kingdom) as a random effect. Thus we ran 49 models representing these combinations. Elevation is never a significant predictor of divergence time in any model, before or after accounting for taxonomy. Before accounting for taxonomy, thermoregulation and locomotion are significant irrespective of elevation. However, models accounting for both thermoregulation and locomotion simultaneously are never significant. The models that are significant before accounting for taxonomy remain significant when Genus, Family, Phylum, or Kingdom ranks are used as the random effect. However, they are not significant when using Order or Class as the random effect. Our interpretation of these results is that there are too many Genera and Families relative to data points, and too few Phyla and Kingdoms, to act as effective random effects. Therefore, this shows evidence that thermoregulation and locomotion are not significant after accounting for taxonomic levels.

\section{Niche Modeling}

We obtained occurrence data for Vireo bellii by downloading all eBird data in May 2017 (Sullivan et al., 2009). We then supplemented this data with data from GBIF, iNaturalist, and VertNet (gbif.org, inaturalist.org, vertnet.org). This was done using custom R scripts that made use of the following packages: 'RASTER' (Hijmans 2017), 'MASS' (Venables and Ripley 2002), 'SPOCC' (Chamberlain 2017), 'RGEOS' (Bivand and Rundel 2017), 'DPLYR' (Wickham et al., 2017), 'SP' (Pebesma and Bivand 2005; Bivand et al., 2013), and 'DISMO' (Hijmans et al., 2017). We removed duplicate localities. Outliers were detected and removed using a probability density function. After this, we thinned the data using 'SPTHIN' (Aiello-Lammens et al., 2014) to account for spatial autocorrelation in the data. This left us with 1,026 occurrence points for the species.

Climate data used was the WorldClim database (Hijmans et al., 2005). We used all 19 variables, but we constrained the climate data to fall within longitude -115.70 to -101.26 and latitude 27.00 to 36.47 . We then took the climate data and the occurrence data and built an ecological niche model using MaxEnT (Phillips et al., 2006) with 'ENMEvaL' as a wrapper function for model selection (Muscarella et al., 2014). 'ENMEVAL' is an R package that optimizes MAXENT models based on different sets of feature classes and regularization values. In particular, we selected between the linear and linear+quadratic feature classes, as well as regularization values of $0.5,1,1.5,2,2.5,3,3.5$, and 4 . Models were run for each combination of feature classes and regularization values, and the model with the lowest occurrence point omission rate and highest area under the curve was chosen. The best model used linear+quadratic feature classes and a regularization value of 0.5 , with an AUC of 0.83 and an omission rate of $14.2 \%$. The second best model also used linear+quadratic features, but had a regularization value of 1 , an AUC of 0.82 , and an omission rate of $22.8 \%$. After the final model was generated and projected back onto the climate data, we converted the suitability values from $0-1$ for SLiM to use and downprojected to an ascii of 57 by 87 grid cells.

\section{$\underline{\text { Slim Simulation Details }}$}

For each of the 32 model sets, we ran 1000-1200 simulations each in SLIM 3 with the exception of the eight models run for 1,000,000 generations. These longer models were 
computationally intense, and so we only ran them 100 times each, to determine whether the patterns we found for 6,000-120,000 generations would continue to hold for longer time periods. Scripts are available at github.com/kaiyaprovost.

We used a mutation rate of $2.21 \times 10^{-9}$ substitutions per site per year (Nam et al., 2010), the suggested default recombination rate in SLIM 3.1, and empirical estimates of ancestral population sizes for a bird with genetic structure across the CFB (Provost et al., 2018). We chose a large gene flow value of $10 \%$ to amplify the effects of introgression within applicable models. We simulated a chromosome of 100,000 base pairs. For models with a phylogeographic split, we divided individuals into two equally sized populations. The spatial boundaries of these populations were constrained by longitude to simulate a barrier; individuals in population 1 were only able to occupy the western $50 \%$ of habitat, and individuals in population 2 were only able to occupy the eastern $50 \%$ (see below).

The niche model was constrained to be between longitude -115.70 to -101.26 , and latitude 27.00 to 36.47 , narrowing in on the transition zone between the deserts. Fitness across the landscape was calculated by taking the cube root of the cell value (which ranged from 0-1) and multiplying it by the relative fitness of the individual; these fitness values are required in SLiM to create new individuals each generation and cause the algorithm to preferentially generate offspring in regions of high ecological niche suitability.

We reduced the computational load of our models by scaling our parameters by a factor (lambda) of 0.02, and by implementing tree sequence recording (Haller et al., 2019). Scaling factors reduce the number of generations and number of individuals to simulate but keep the relative mutation rate and recombination rate constant. We chose 0.02 as it improved our performance without impacting the distribution of summary statistics in preliminary runs (Table S1.1). Tree sequence recording tracks the true ancestry of every position in the simulated chromosome across individuals rather than explicitly simulating mutations (Haller et al., 2019). Individuals who do not have any descendents are removed. We modeled neutral variation from the tree sequences using our scaled mutation rate, then converted the tree sequences to VCF format (Danecek et al., 2011) and MS format (Stevison 2014). MS format summarizes the number of segregating sites, the positions with polymorphic sites, and the haplotypes of every individual where a zero indicates the ancestral state and a 1 indicates the derived state. When converting to MS format, we randomly sampled 20 diploid individuals, 10 from the eastern side of the barrier and 10 from the western.

We generated 33 summary statistics originally (Table S1.2). Many of these summary statistics are highly correlated with each other. There is some evidence to suggest that neural networks can suffer from multicollinearity issues (Cheng et al., 2018). As such we ran the neural network with all summary statistics as well as with a reduced set that only contained statistics correlated with an absolute correlation coefficient less than 0.75 . This gave us 11 summary statistics (Table S1.2). In some cases, simulations produced duplicate summary statistic information, in that independent runs of the simulation generated the exact same 33 summary statistics upon output, likely because the same random seed was generated. We removed these duplicates going forward to avoid overfitting.

\section{Machine Learning Details}

Our neural network used the LBFGS (Byrd et al., 1995) algorithm as its solver and had an adaptive learning rate, where the rate of learning decreased as the iterations increased. The 
learning rate was initialized at 0.0001 . There were 1,000 maximum iterations allowed. The hidden layer was constrained to be three layers each of 100 nodes, which was chosen after testing between it and eight other configurations (one layer of five, 25, and 100 nodes; two layers of five, 25, and 100 nodes; three layers of five, 25, and 100 nodes) to determine which performed best at classifying our validation data. The alpha parameter, which penalizes complexity, was tested across values $0,0.01,0.1,1$, and 10 ; to choose between these, we ran the neural network five times while varying the alpha value, and the network with the highest accuracy was chosen. Running the neural networks with the 33 summary statistics rather than the 11 summary statistics marginally changed our models; they decreased model accuracy across all model runs, improved compute time, and resulted in less overfitting. As such we only present model results using 11 summary statistics unless otherwise specified.

Machine learning algorithms have broadly been shown to have high accuracy in classifying models. The suite tools developed to utilize these algorithms have been used broadly in biological contexts, for example to aid in sound identification (Juang and Chen 2007) and image processing (Wei et al., 2018) as well as for the classification purposes we use them for here (Sukumaran et al., 2016). Despite these strengths, it is not known how well the simulations classify actual genetic data, as that was outside the scope of this study. Further, regardless of how hypotheses are generated and tested, some biological scenarios will still be difficult to tell apart even with powerful and state-of-the-art simulation software and analytical techniques (see main text; Roux et al., 2016). 
bioRxiv preprint doi: https://doi.org/10.1101/2020.06.17.157842; this version posted June 18, 2020. The copyright holder for this preprint (which was not certified by peer review) is the author/funder. All rights reserved. No reuse allowed without permission.

\section{Supplementary Figures and Tables}

Table S1.1: Parameters used in the simulated demographic models. "Gens" =generations. Scaled with a lambda $=0.02$.

\begin{tabular}{|c|c|c|}
\hline Parameter & Original Value & Scaled Value \\
\hline Effective Population Size (Ne) & 400,000 & 8,000 \\
\hline Mutation rate (per base per gen) & $2.21 \times 10^{-9}$ & $1.11 \times 10^{-7}$ \\
\hline Recombination (per base per gen) & $1 \times 10^{-8}$ & $5 \times 10^{-7}$ \\
\hline Number of Gens. & 6,000 & 120 \\
& 21,000 & 420 \\
& 120,000 & 2,400 \\
& $1,000,000$ & 20,000 \\
\hline Gens. of Secondary Contact & 1,000 & 20 \\
\hline
\end{tabular}


Table S1.2: Summary statistics used as inputs to our neural network. Asterisks next to variable names indicate that the variable was kept in the 11-statistic, non-collinear dataset. "P1" and "P2" stand for population 1 and population 2 , respectively.

\begin{tabular}{|c|c|}
\hline Variable Name & Description \\
\hline div_per_site* & Calculated nucleotide diversity per site \\
\hline fu.li.d* & Fu and Li's D \\
\hline fu.li.d.1 & Above, but calculated assuming two populations \\
\hline fu.li.f & Fu and Li’s F \\
\hline fu.li.f.1 & Above, but calculated assuming two populations \\
\hline hap.diversity.within* & Haplotype diversity within populations \\
\hline kurt haplotype.counts* & Kurtosis of all frequencies of haplotype counts \\
\hline kurt minor.allele.freqs & Kurtosis of all minor allele frequencies \\
\hline mean_haplotype.counts* & Mean of all frequencies of haplotype counts \\
\hline mean minor.allele.freqs & Mean of all minor allele frequencies \\
\hline mean_nuc.diversity.within & Mean of nucleotide diversity within populations \\
\hline n.biallelic.sites & The number of biallelic sites \\
\hline n.segregating.sites* & The number of segregating sites in $\mathrm{P} 1$ \\
\hline n.segregating.sites. 1 & Above, but for P2 \\
\hline n.sites* & The number of sites total \\
\hline pi & Nucleotide diversity \\
\hline skew_haplotype.counts & Skew of all frequencies of haplotype counts \\
\hline skew minor.allele.freqs* & Skew of all minor allele frequencies \\
\hline skew_nuc.diversity.within & Skew of nucleotide diversity within populations \\
\hline tajima.d & Tajima's D for P1 \\
\hline tajima.d. ${ }^{*}$ & Above, but for $\mathrm{P} 2$ \\
\hline theta_achaz.tajima & Achaz's Tajima's D accounting for sequencing error in P1 \\
\hline theta_achaz.tajima. ${ }^{*}$ & Above, but for P2 \\
\hline theta_achaz.watterson & Achaz's Watterson's Theta accounting for error in P1 \\
\hline theta achaz.watterson. 1 & Above, but for P2 \\
\hline theta_fu.li & Fu and Li's Theta in P1 \\
\hline theta_fu.li. ${ }^{*}$ & Above, but for $\mathrm{P} 2$ \\
\hline theta tajima & Tajima's Theta \\
\hline theta_watterson & Watterson's Theta in P1 \\
\hline theta_watterson.1 & Above, but for $\mathrm{P} 2$ \\
\hline var_haplotype.counts & Variance of all frequencies of haplotype counts \\
\hline var_minor.allele.freqs & Variance of all minor allele frequencies \\
\hline var nuc.diversity.within & Variance of nucleotide diversity within populations \\
\hline
\end{tabular}


Table S1.3: Synthesis of previously published phylogeographic studies. Loco = locomotion types $(\mathrm{W}=$ walking, $\mathrm{J}=$ jumping, $\mathrm{F}=$ flying, $\mathrm{C}=$ crawling, $\mathrm{SM}=$ swimming, $\mathrm{SS}=$ sessile $)$. Therm = thermoregulation types $(\mathrm{CT}=$ ectotherm, $\mathrm{DC}=$ endotherm $) . \mathrm{Str}=$ structure across $\mathrm{CFB}(\mathrm{N}=$ no, $\mathrm{Y}=$ yes $)$. West and East are most extreme longitudes of contact zones. Time $=$ divergence times $(\mathrm{M}=$ Miocene, $\mathrm{PL}=$ Pliocene, $\mathrm{PS}=$ Pleistocene $) . \mathrm{GF}=$ gene flow $(\mathrm{N}=$ no, $\mathrm{Y}=$ yes $)$. Mono = monophyletic or not $(\mathrm{N}=$ no, $\mathrm{Y}=$ yes $)$. Mode = mode of speciation $(\mathrm{A}=$ allopatry, Ecological, $\mathrm{S}=$ sexual selection, $\mathrm{H}=$ hybridization, $\mathrm{P}=$ polyploidy). See footnote for reference numbers.

\begin{tabular}{|c|c|c|c|c|c|c|c|c|c|c|c|}
\hline Taxa & Loco & Therm & Elev & Str & West & East & Time & GF & Mono & Mode & Refs \\
\hline Agelenopsis aperta & $\mathrm{W}$ & $\mathrm{CT}$ & $\mathrm{D}$ & $\mathrm{N}$ & & & PS & & & & 1 \\
\hline Agonum extensicolle & W & CT & D M & Y & & & & & Y & A & 2 \\
\hline $\begin{array}{l}\text { Ammospermophilus } \\
\text { complex }\end{array}$ & W & ND & $\mathrm{D}$ & $\mathrm{N}$ & & & PL PS & & $\mathrm{N}$ & & 3 \\
\hline Anaxyrus punctatus & $\mathrm{J}$ & $\mathrm{CT}$ & $\mathrm{D}$ & $\mathrm{Y}$ & -109.205 & -108.857 & PS & & $\mathrm{Y}$ & $\mathrm{A}$ & 4,5 \\
\hline Antrozous pallidus & $\mathrm{F}$ & ND & $\mathrm{D} M$ & $\mathrm{Y}$ & -109.13 & -108.58 & PL PS & & $\mathrm{Y}$ & $\mathrm{A}$ & 6 \\
\hline Arizona elegans & $\mathrm{C}$ & CT & $\mathrm{D}$ & $\mathrm{Y}$ & -109.5721 & -103.75 & M PL & & $\mathrm{Y}$ & $\mathrm{E}$ & $7,8,9$ \\
\hline Auriparus flaviceps & $\mathrm{F}$ & ND & $\mathrm{D}$ & $\mathrm{N}$ & & & & $\mathrm{N}$ & $\mathrm{N}$ & & 10,11 \\
\hline Callipepla genus & $\mathrm{F}$ & ND & $\mathrm{D}$ & $\mathrm{Y}$ & & & PL & & $\mathrm{Y}$ & & 12 \\
\hline $\begin{array}{l}\text { Campylorhynchus } \\
\text { brunneicapillus }\end{array}$ & $\mathrm{F}$ & ND & $\mathrm{D}$ & $\mathrm{N}$ & & & & $\mathrm{N}$ & $\mathrm{N}$ & & $10,11,13$ \\
\hline Cardinalis cardinalis & $\mathrm{F}$ & ND & $\mathrm{D}$ & $\mathrm{Y}$ & -108.4975 & -103.8765 & PS & $\mathrm{Y}$ & $\mathrm{Y}$ & $\mathrm{A}$ & 14,15 \\
\hline Certhia americana & $\mathrm{F}$ & ND & M & $\mathrm{N}$ & & & PS & & $\mathrm{N}$ & & 16 \\
\hline Chaetodipus hispidus & $\mathrm{W}$ & ND & $\mathrm{D}$ & $\mathrm{Y}$ & -108.5 & -99.49818 & PL & & $\mathrm{Y}$ & $\mathrm{A}$ & 17 \\
\hline Chaetodipus intermedius & W & ND & $\mathrm{D} M$ & $\mathrm{Y}$ & & & PL PS & & $\mathrm{Y}$ & $\mathrm{A}$ & $18,19,20$ \\
\hline $\begin{array}{c}\text { Chaetodipus penicillatus, } \\
\text { C. eremicus } \\
\end{array}$ & $\mathrm{W}$ & ND & $\mathrm{D}$ & $\mathrm{Y}$ & -108.66 & -104.49 & PS & & $\mathrm{Y}$ & A & $18,21,22$ \\
\hline $\begin{array}{c}\text { Colaptes chrysoides, } \\
\text { C. auratus }\end{array}$ & $\mathrm{F}$ & ND & D M & & & & PS & Y & & & $10,23,24,25$ \\
\hline $\begin{array}{c}\text { Corvus corax, } C . \\
\text { cryptoleucus } \\
\end{array}$ & $\mathrm{F}$ & ND & $\mathrm{D} M$ & & & & PS & $\mathrm{Y}$ & $\mathrm{N}$ & & \begin{tabular}{|c|}
$26,27,28,29$ \\
30,31 \\
\end{tabular} \\
\hline Crotalus atrox & $\mathrm{C}$ & $\mathrm{CT}$ & $\mathrm{D}$ & & & & PL & $\mathrm{Y}$ & $\mathrm{Y}$ & $\mathrm{E}$ & $7,9,32,33,34$ \\
\hline Crotalus molossus & $\mathrm{C}$ & $\mathrm{CT}$ & $\mathrm{M}$ & $\mathrm{Y}$ & -112.8209 & -103.4542 & PL & & $\mathrm{Y}$ & $\mathrm{E}$ & $7,9,35$ \\
\hline Crotalus scutulatus & $\mathrm{C}$ & CT & $\mathrm{D}$ & $\mathrm{Y}$ & -108.9485 & -105.59 & PS & & $\mathrm{Y}$ & $\mathrm{E}$ & $7,9,36$ \\
\hline Crotalus viridis complex & $\mathrm{C}$ & CT & M & $\mathrm{Y}$ & -111.3753 & -106.5556 & & & $\mathrm{Y}$ & & $37,38,39,40$ \\
\hline \begin{tabular}{|c|} 
Cucurbita palmata, \\
C. digitata \\
\end{tabular} & SS & CT & $\mathrm{D} M$ & $\mathrm{Y}$ & & & PS & & $\mathrm{Y}$ & $\mathrm{A}$ & 41 \\
\hline Dilophotopsis complex & $\mathrm{W}$ & $\mathrm{CT}$ & $\mathrm{D}$ & $\mathrm{Y}$ & -116.3650 & -112.905 & PL & & & $\mathrm{A}$ & 42,43 \\
\hline Dryobates pubescens & $\mathrm{F}$ & ND & $\mathrm{M}$ & $\mathrm{N}$ & & & & & & & $10,44,45,46$ \\
\hline Dryobates villosus & $\mathrm{F}$ & ND & $\mathrm{M}$ & $\mathrm{N}$ & & & PS & & $\mathrm{N}$ & & 47 \\
\hline Gambelia wislizenii & $\mathrm{W}$ & $\mathrm{CT}$ & $\mathrm{D}$ & $\mathrm{Y}$ & -113.98 & -108.65 & PL PS & & $\mathrm{Y}$ & $\mathrm{A}$ & 48 \\
\hline Gastrophryne olivacea & $\mathrm{J}$ & CT & $\mathrm{D}$ & $\mathrm{Y}$ & -111.2715 & -105.1958 & PS & & $\mathrm{Y}$ & & 49 \\
\hline Gryllus complex & $\mathrm{J}$ & CT & $\mathrm{D} M$ & $\mathrm{Y}$ & -113.2537 & -106.8939 & & & $\mathrm{~N}$ & A S & 50 \\
\hline Hypsiglena torquata & $\mathrm{C}$ & $\mathrm{CT}$ & $\mathrm{D}$ & $\mathrm{Y}$ & -111.0230 & -109.3432 & $\mathrm{M}$ & $\mathrm{Y}$ & $\mathrm{Y}$ & & $7,9,51,52$ \\
\hline Kinosternon flavescens & SM & CT & $\mathrm{D}$ & $\mathrm{Y}$ & -111.5420 & -108.5336 & M PL & & $\mathrm{Y}$ & A & 53 \\
\hline Lampropeltis getula & $\mathrm{C}$ & $\mathrm{CT}$ & $\mathrm{D}$ & $\mathrm{Y}$ & -109.8899 & -109.0344 & PL & & $\mathrm{Y}$ & $\mathrm{E}$ & $7,54,55$ \\
\hline $\begin{array}{c}\text { Lampropeltis } \\
\text { pyromelana complex }\end{array}$ & $\mathrm{C}$ & $\mathrm{CT}$ & & & & & PL & $\mathrm{Y}$ & & $\mathrm{E}$ & 56 \\
\hline \begin{tabular}{|c|} 
Lampropeltis splendida, \\
L. californiae \\
\end{tabular} & $\mathrm{C}$ & CT & & & & & PS & $\mathrm{Y}$ & & $\mathrm{E}$ & 56 \\
\hline Lophocereus schottii & SS & $\mathrm{CT}$ & $\mathrm{D}$ & & & & & & & & 57 \\
\hline Masticophis flagellum & $\mathrm{C}$ & $\mathrm{CT}$ & $\mathrm{D}$ & $\mathrm{Y}$ & -110.2167 & -109.1358 & M PL & $\mathrm{Y}$ & $\mathrm{Y}$ & $\mathrm{E}$ & $7,9,58,59$ \\
\hline $\begin{array}{c}\text { Melampodium } \\
\text { leucanthum }\end{array}$ & SS & CT & $\mathrm{D} M$ & $\mathrm{Y}$ & -110.253 & -104.857 & PS & $\mathrm{Y}$ & $\mathrm{Y}$ & A P & 60 \\
\hline
\end{tabular}


bioRxiv preprint doi: https://doi.org/10.1101/2020.06.17.157842; this version posted June 18, 2020. The copyright holder for this preprint (which was not certified by peer review) is the author/funder. All rights reserved. No reuse allowed without permission.

\begin{tabular}{|c|c|c|c|c|c|c|c|c|c|c|c|}
\hline Melozone fusca & $\mathrm{F}$ & ND & $\bar{D}$ & $\bar{Y}$ & -109.0490 & -103.0644 & PS & $\mathrm{N}$ & $\bar{Y}$ & $\mathrm{AE}$ & $10,11,61,62$ \\
\hline Moneilema appressum & $\mathrm{W}$ & $\mathrm{CT}$ & D M & & & & PS & & & & 63 \\
\hline Myotis spp. & $\mathrm{F}$ & ND & $\mathrm{D} M$ & $\mathrm{~N}$ & & & & & $\mathrm{~N}$ & & 64 \\
\hline Notiosorex crawfordi & $\mathrm{W}$ & ND & D M & $\mathrm{Y}$ & -111.04 & -109.21 & & & Y & & 65 \\
\hline $\begin{array}{c}\text { Odocoileus hemionus } \\
\text { complex }\end{array}$ & $\mathrm{W}$ & ND & $\mathrm{D} M$ & & & & & & $\mathrm{~N}$ & & 66 \\
\hline Onychomys complex & $\mathrm{W}$ & ND & $\mathrm{D}$ & $\mathrm{Y}$ & -118.33 & -107.15 & & & $\mathrm{Y}$ & $\mathrm{A}$ & 67 \\
\hline Peromyscus eremicus & $\mathrm{W}$ & ND & $\mathrm{D} M$ & $\mathrm{Y}$ & -108.7410 & -105.27 & PS & & $\mathrm{Y}$ & $\mathrm{A}$ & $19,68,69$ \\
\hline Phrynosoma cornutum & $\mathrm{W}$ & CT & D & Y & -109.67 & -104.21 & PL PS & & & A & 70 \\
\hline $\begin{array}{c}\text { Phrynosoma cornutum } \\
\text { complex }\end{array}$ & W & CT & D & Y & & & & & Y & & 71 \\
\hline $\begin{array}{c}\text { Phrynosoma hernandesi } \\
\text { complex }\end{array}$ & W & $\mathrm{CT}$ & D M & & & & & & $\mathrm{Y}$ & & 71 \\
\hline $\begin{array}{c}\text { Phrynosoma modestum } \\
\text { complex }\end{array}$ & W & $\mathrm{CT}$ & $\mathrm{D}$ & $\mathrm{Y}$ & & & & & $\mathrm{Y}$ & & 71 \\
\hline $\begin{array}{c}\text { Phrynosoma orbiculare } \\
\text { complex }\end{array}$ & W & $\mathrm{CT}$ & $\mathrm{D} M$ & & & & & & $\mathrm{Y}$ & & 71 \\
\hline Pituophis catenifer & $\mathrm{C}$ & $\mathrm{CT}$ & $\mathrm{D} M$ & $\mathrm{Y}$ & -109.4382 & -108.0766 & PL & & $\mathrm{Y}$ & & $7,9,72,73$ \\
\hline $\begin{array}{c}\text { Pogonomyrmex } \\
\text { barbatus, } \text { P. rugosus }\end{array}$ & W & $\mathrm{CT}$ & $\mathrm{D} M$ & $\mathrm{Y}$ & -109.2333 & -108.3666 & & $\mathrm{Y}$ & $\mathrm{Y}$ & $\mathrm{AH}$ & 74 \\
\hline Polioptila melanura & $\mathrm{F}$ & ND & $\mathrm{D}$ & $\mathrm{N}$ & & & & $\mathrm{Y}$ & $\mathrm{N}$ & & $10,11,75$ \\
\hline Pseudotsuga menziesii & SS & CT & M & $\mathrm{N}$ & & & PS & & $\mathrm{N}$ & & 76,77 \\
\hline $\begin{array}{c}\text { Pseudouroctonus savvasi } \\
\text { complex }\end{array}$ & W & $\mathrm{CT}$ & $\mathrm{D} M$ & $\mathrm{Y}$ & -106.423 & -104.785 & M & & & $\mathrm{A}$ & 78 \\
\hline Rhinocheilus lecontei & $\mathrm{C}$ & $\mathrm{CT}$ & $\mathrm{D}$ & $\mathrm{Y}$ & -106.9927 & -100.5309 & PL & & $\mathrm{Y}$ & E & $7,8,9,70$ \\
\hline Salvadora hexalepis & $\mathrm{C}$ & $\mathrm{CT}$ & $\mathrm{D}$ & & & & PS & & $\mathrm{Y}$ & E & 7,9 \\
\hline Sceloporus magister & $\mathrm{W}$ & $\mathrm{CT}$ & $\mathrm{D}$ & $\mathrm{Y}$ & -109.0731 & -106.8828 & PL & $\mathrm{Y}$ & $\mathrm{Y}$ & & 79 \\
\hline Sciurus aberti & $\mathrm{W}$ & ND & $\mathrm{M}$ & $\mathrm{Y}$ & -109.67 & -107.48 & PS & & $\mathrm{Y}$ & $\mathrm{A}$ & 80 \\
\hline Sitta carolinensis & $\mathrm{F}$ & ND & M & $\mathrm{N}$ & & & PS & & $\mathrm{N}$ & & 81 \\
\hline Sonora semiannulata & $\mathrm{C}$ & $\mathrm{CT}$ & $\mathrm{D}$ & $\mathrm{Y}$ & -110.6524 & -101.2193 & & $\mathrm{Y}$ & & E & 9,82 \\
\hline Spilogale gracilis & $\mathrm{W}$ & ND & $\mathrm{M}$ & $\mathrm{Y}$ & -109.3515 & -105.9272 & PS & & $\mathrm{Y}$ & A & 83 \\
\hline Thamnophis marcianus & $\mathrm{C}$ & $\mathrm{CT}$ & $\mathrm{D}$ & & -107.7663 & -104.6466 & PS & & $\mathrm{Y}$ & $\mathrm{E}$ & 7,9 \\
\hline $\begin{array}{c}\text { Thomomys bottae } \\
\text { complex }\end{array}$ & $\mathrm{W}$ & ND & $\mathrm{D} M$ & & & & PS & $\mathrm{Y}$ & $\mathrm{N}$ & & 84 \\
\hline Toxostoma curvirostre & $\mathrm{F}$ & ND & $\mathrm{D}$ & $\mathrm{Y}$ & -108.86 & -104.75 & PS & & $\mathrm{Y}$ & $\mathrm{A} \mathrm{E}$ & $\begin{array}{c}11,61,85,86, \\
87\end{array}$ \\
\hline Toxostoma lecontei & $\mathrm{F}$ & $\mathrm{ND}$ & $\mathrm{D}$ & $\mathrm{N}$ & & & & & $\mathrm{N}$ & & $\begin{array}{c}10,88,89,90, \\
91 \\
\end{array}$ \\
\hline Trimorphodon biscutatus & $\mathrm{C}$ & $\mathrm{CT}$ & $\mathrm{D} M$ & $\mathrm{~N}$ & & & PS & & $\mathrm{N}$ & & $7,9,92,93,94$ \\
\hline Urosaurus ornatus & W & $\mathrm{CT}$ & D M & $\mathrm{Y}$ & -109.16 & -104.68 & PS & $\mathrm{N}$ & $\mathrm{Y}$ & & 95 \\
\hline Vaejovis vorhiesi & W & CT & M & $\mathrm{Y}$ & -112.1830 & -109.8627 & M & & Y & A & 96 \\
\hline Vireo bellii & $\mathrm{F}$ & ND & $\mathrm{D}$ & $\mathrm{Y}$ & -108.795 & -104.6851 & PS & $\mathrm{N}$ & $\mathrm{Y}$ & $\mathrm{A}$ & 97 \\
\hline Xantusia complex & W & CT & D M & & & & & & & & 98 \\
\hline
\end{tabular}

[1] Ayoub and Riechert 2004. [2] Liebherr 1986. [3] Mantooth et al., 2013. [4] Jaeger et al., 2005. [5] Bryson Jr et al., 2012. [6] Weyandt and Van Den Bussche 2007. [7] Myers et al., 2017b. [8] Dahn et al., 2018. [9] Myers et al., 2019b. [10] Zink 1996. [11] Zink et al., 2001. [12] Hosner et al., 2015. [13] Teutimez 2012. [14] Smith et al., 2011. [15] Provost et al., 2018. [16] Manthey et al., 2011. [17] Andersen and Light 2012. [18] Riddle 1995. [19] Riddle et al., 2000a. [20] Hoekstra et al., 2005. [21] Lee et al., 1996. [22] Jezkova et al., 2009. [23] Moore et al., 1991. [24] Manthey et al., 2017. [25] Aguillon et al., 2018. [26] Omland et al., 2000. [27] Omland et al., 2006. [28] Webb et al., 2011. [29] Haring et al., 2012. [30] Johnsen et al., 2017. [31] Kearns et al., 2018. [32] Castoe et al., 2007. [33] Schield et al., 2015. [34] Schield et al., 2017. [35] Anderson and Greenbaum 2012. [36] Schield et al., 2018. [37] Ashton and de Queiroz 2001. [38] Davis et al., 2016. [39] Pook et al., 2000. [40] Douglas and Schuett 2002. [41] Castellanos-Morales et al., 2018. [42] Wilson and Pitts 2008. [43] Wilson and Pitts 2010. [44] Ball and Avise 1992. [45] Pulgarín-Restrepo 2011. [46] Pulgarín-Restrepo and Burg 2012. [47] Klicka et al., 2011. [48] Orange et al., 1999. [49] Streicher et al., 2012. [50] Gray et al., 2016. [51] Mulcahy 2008. [52] Mulcahy and Macey 2009. [53] Serb et al., 2001. [54] Pyron and Burbrink 2009. [55] Myers et al., 2019a. [56] Burbrink and Gehara 2018. [57] Nason et al., 2002. [58] Myers et al., 2017a. [59] O'Connell et al., 2017. [60] Rebernig 
bioRxiv preprint doi: https://doi.org/10.1101/2020.06.17.157842; this version posted June 18, 2020. The copyright holder for this preprint (which was not certified by peer review) is the author/funder. All rights reserved. No reuse allowed without permission.

et al., 2010. [61] Zink 2014. [62] Zink and Klicka 2000. [63] Smith and Farrell 2005. [64] Rodriguez and Ammerman 2004. [65] McAliley et al., 2007. [66] Latch et al., 2009. [67] Riddle and Honeycutt 1990. [68] Walpole et al., 1997. [69] Riddle et al., 2000b. [70] Rosenthal and Forstner 2004. [71] Leaché and McGuire 2006. [72] Bryson Jr et al., 2011a. [73] Bryson Jr et al., 2011b. [74] Mott et al., 2015. [75] Smith et al., 2018. [76] Gugger et al., 2010. [77] Gugger et al., 2011. [78] Bryson Jr et al., 2013b. [79] Leaché and Mulcahy 2007. [80] Lamb et al., 1997. [81] Spellman and Klicka 2007. [82] Cox et al., 2018. [83] Ferguson et al., 2017. [84] Belfiore et al., 2008. [85] Zink and Blackwell-Rago 2000. [86] Rojas-Soto 2003. [87] Rojas-Soto et al., 2007. [88] Zink et al., 1999. [89] Zink et al., 1997. [90] Lovette et al., 2012. [91] Vazquez-Miranda et al., 2017. [92] LaDuc and Johnson 2003. [93] Devitt 2006. [94] Devitt et al., 2008. [95] Haenel 2007. [96] Bryson Jr et al., 2013a. [97] Klicka et al., 2016. [98] Sinclair et al., 2004.

Table S1.4: Model results for all 33 statistics. Accuracy scores are calculated for phylogeographic structure alone (P), IBD alone (I), and ages alone (A) when applicable. "Gens." =generations. "Acc." =accuracy.

\begin{tabular}{|c|c|c|c|c|c|c|c|}
\hline Gens. & Dataset & Precision & Recall & F-score & Acc. $($ P) & Acc. (I) & Acc. (A) \\
\hline 6,000 & Training & 0.75 & 0.75 & 0.75 & 0.75 & 1.00 & $\mathrm{n} / \mathrm{a}$ \\
\hline 6,000 & Validation & 0.24 & 0.24 & 0.24 & 0.30 & 0.84 & $\mathrm{n} / \mathrm{a}$ \\
\hline 6,000 & Test & 0.24 & 0.24 & 0.24 & 0.28 & 0.81 & $\mathrm{n} / \mathrm{a}$ \\
\hline 21,000 & Training & 0.87 & 0.87 & 0.87 & 0.88 & 0.98 & $\mathrm{n} / \mathrm{a}$ \\
\hline 21,000 & Validation & 0.29 & 0.29 & 0.29 & 0.35 & 0.85 & $\mathrm{n} / \mathrm{a}$ \\
\hline 21,000 & Test & 0.29 & 0.29 & 0.29 & 0.36 & 0.84 & $\mathrm{n} / \mathrm{a}$ \\
\hline 120,000 & Training & 0.92 & 0.92 & 0.92 & 0.93 & 0.99 & $\mathrm{n} / \mathrm{a}$ \\
\hline 120,000 & Validation & 0.41 & 0.41 & 0.41 & 0.46 & 0.89 & $\mathrm{n} / \mathrm{a}$ \\
\hline 120,000 & Test & 0.41 & 0.41 & 0.41 & 0.47 & 0.87 & $\mathrm{n} / \mathrm{a}$ \\
\hline $1,000,000$ & Training & 0.93 & 0.93 & 0.93 & 0.94 & 0.98 & $\mathrm{n} / \mathrm{a}$ \\
\hline $1,000,000$ & Validation & 0.54 & 0.53 & 0.53 & 0.57 & 0.89 & $\mathrm{n} / \mathrm{a}$ \\
\hline $1,000,000$ & Test & 0.51 & 0.51 & 0.50 & 0.64 & 0.81 & $\mathrm{n} / \mathrm{a}$ \\
\hline All & Training & 0.54 & 0.54 & 0.53 & 0.64 & 0.94 & 0.85 \\
\hline All & Validation & 0.22 & 0.23 & 0.22 & 0.38 & 0.84 & 0.68 \\
\hline All & Test & 0.20 & 0.21 & 0.20 & 0.35 & 0.83 & 0.66 \\
\hline
\end{tabular}




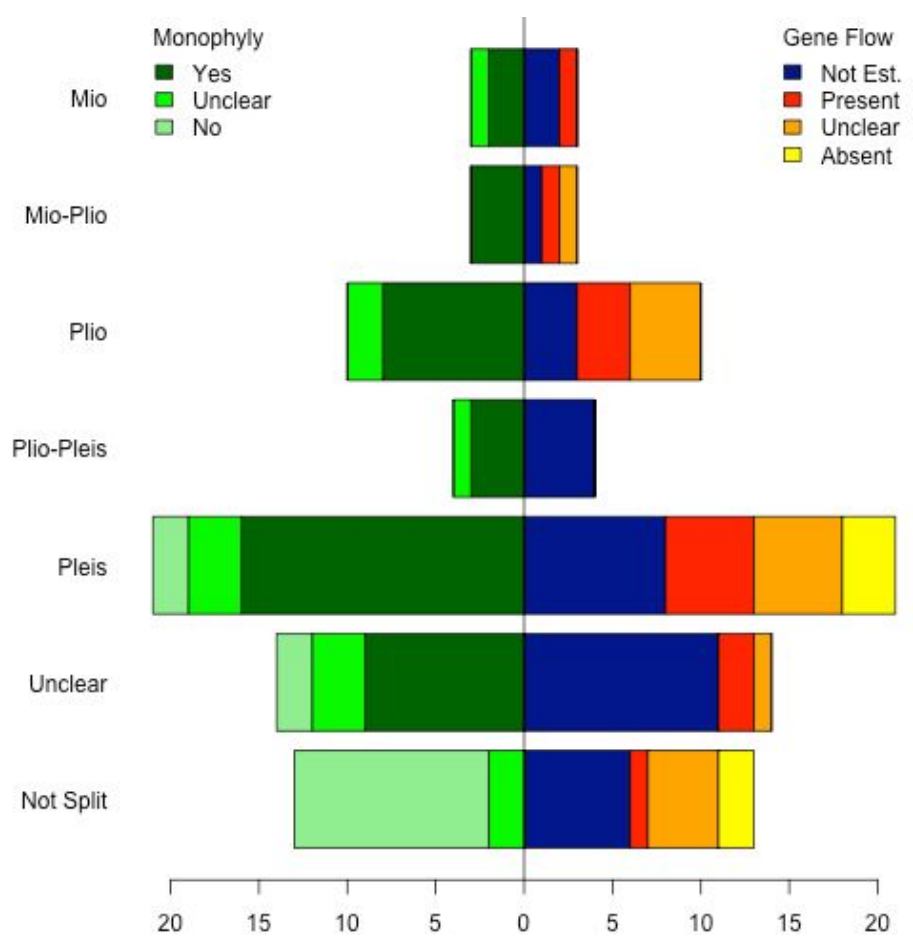

Figure S1.1: Most of the studied taxa across the Cochise Filter Barrier split during the Pleistocene and did not have gene flow assessed. Monophyly and gene flow assessment varies across taxa and across time. Y-axis shows the timing of the split across the Cochise Filter Barrier (if present). X-axis shows the number of taxa that fall into each category. Left side of the figure shows whether monophyly across the CFB in the taxa is present (dark green), unclear (bright green), or absent (pale green). Right side of the figure shows gene flow. Colors indicate if gene flow is unestimated (dark blue), present (red), unclear (orange), or absent (yellow). 

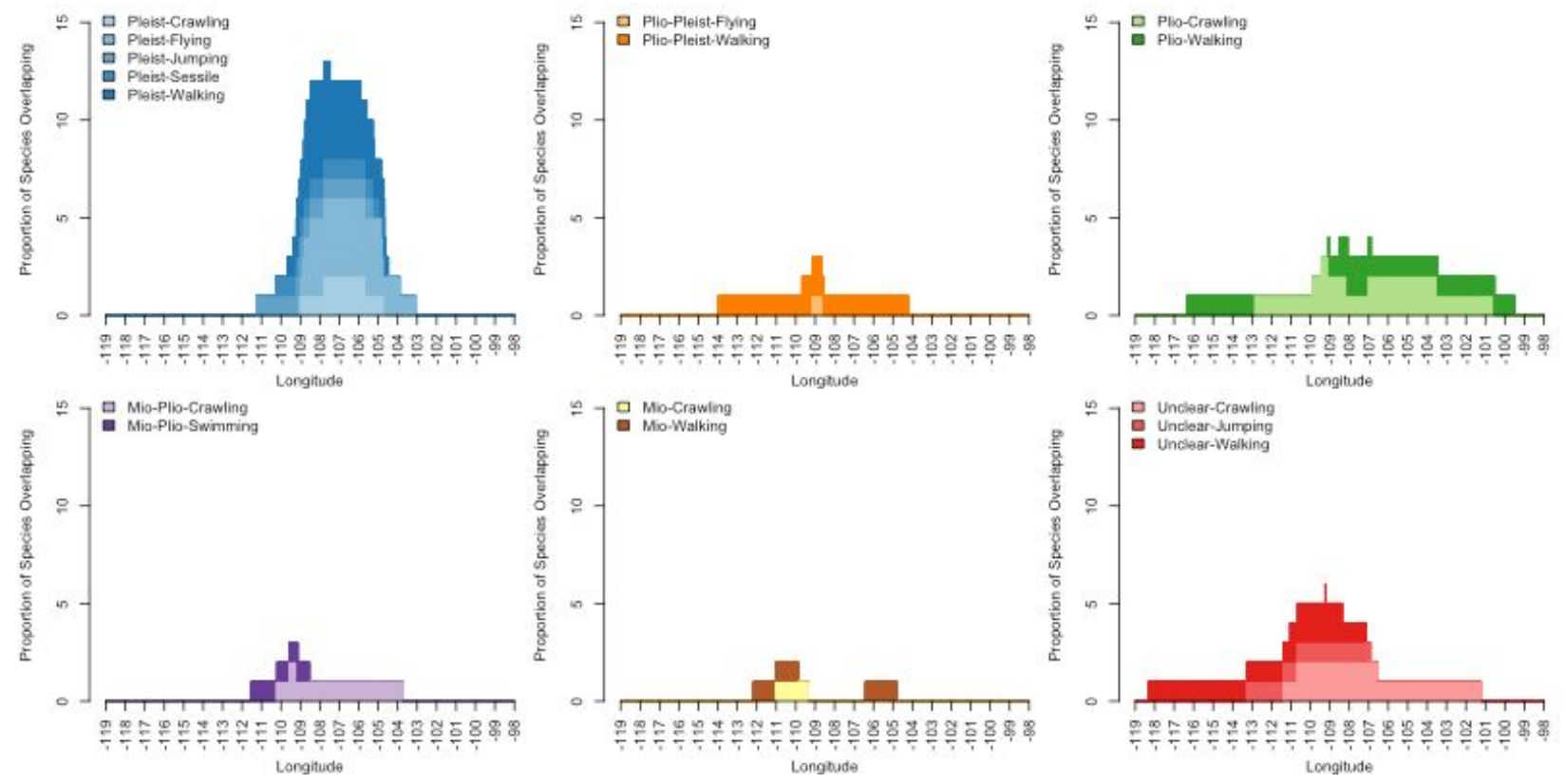

Figure S1.2: Taxa that diverge in the Pliocene show a wider CFB than taxa that diverge in other time frames. Colors, hues, and shades as in Figure 3. Top panels from left to right: Pleistocene, Pliocene, and Plio-Pleistocene. Bottom panels from left to right: Mio-Pliocene, Unknown, and Miocene.
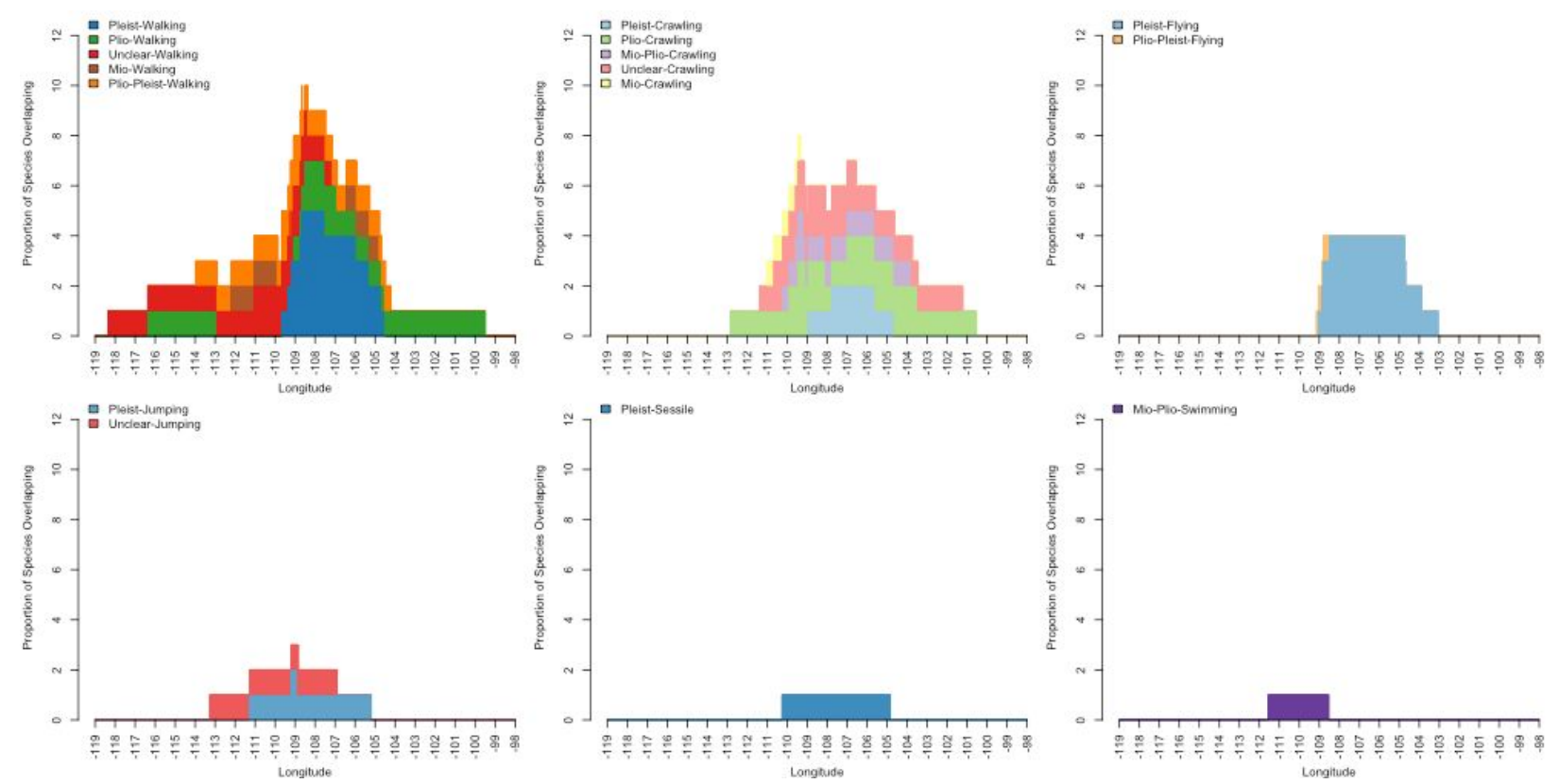

Figure S1.3: Taxa that walk show a wider CFB than taxa that crawl or fly. Colors, hues, and shades as in Figure 3. Top panels from left to right: crawling, flying, and jumping. Bottom panels from left to right: sessile, walking, and swimming. 

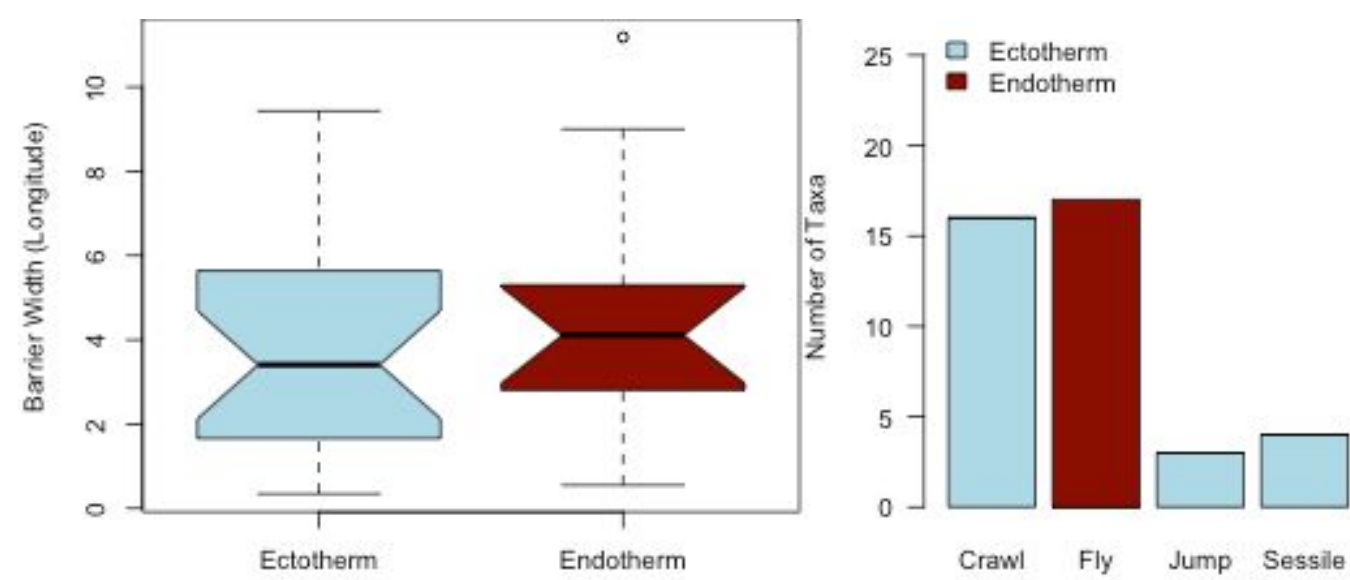

Crawl

Fly

Jump

Sessile

Swim Walk
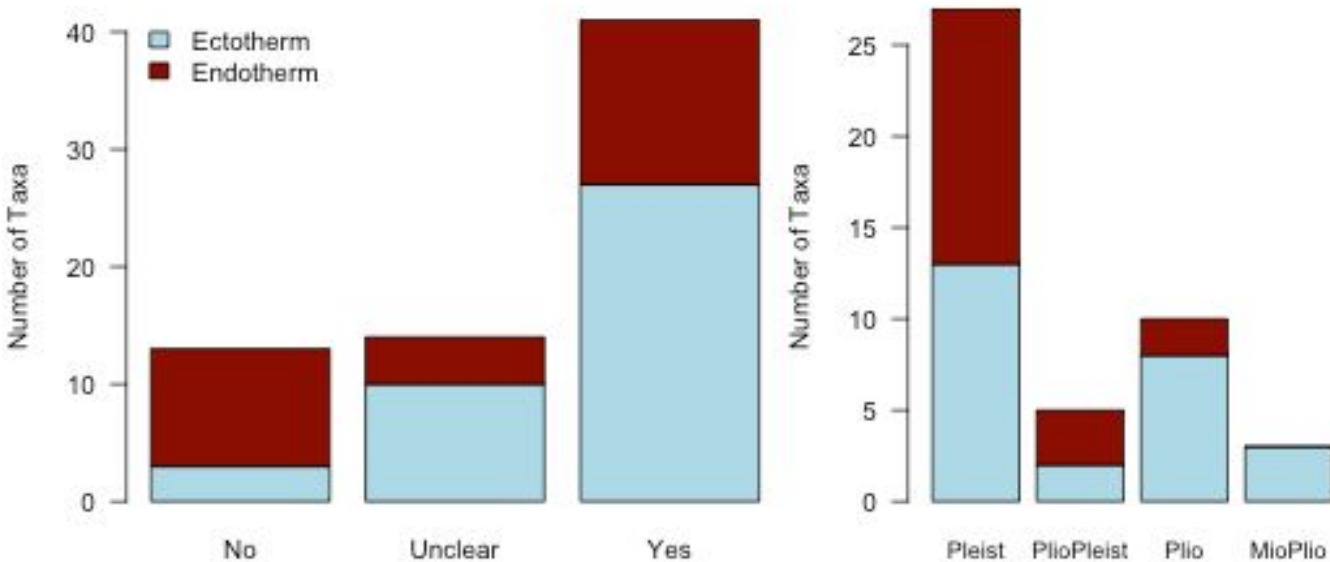

$$
\square \text { Ectotherm }
$$

- Endotherm

Pleist PlioPleist Plio MioPlio Mio Unclear

Figure S1.4. Endothermic species (blue-grey) show more consistent contact zone widths, proportionately less phylogeographic structure, and younger divergence times than ectothermic species (dark red). Top left: boxplot showing the width of the barrier's contact zone (longitude) between ecto- and endo-thermic species. Top right: number of species with different locomotion types that are ecto- or endo-thermic. Bottom left: the number of taxa that show presence, absence, or ambiguous phylogeographic structure (see legend colors) for endo- and ecto-thermic species. Bottom right: divergence epochs for taxa with phylogeographic structure colored by endo- and ecto-thermic species. 


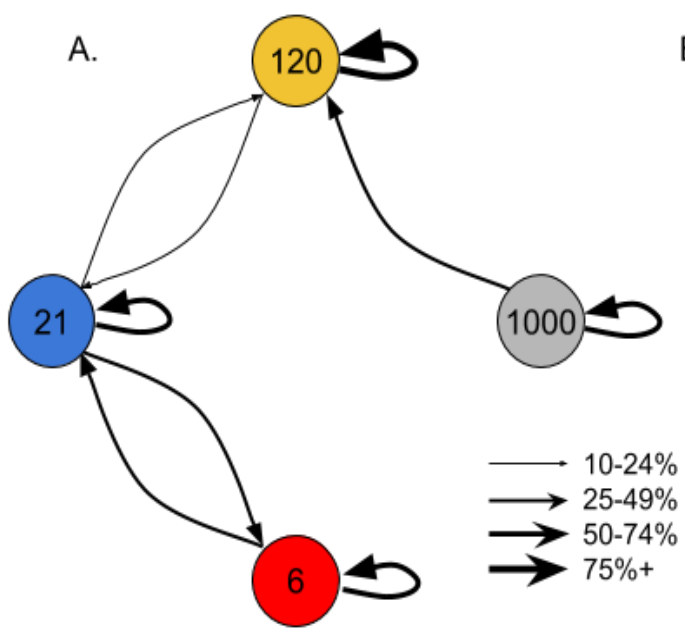

B.

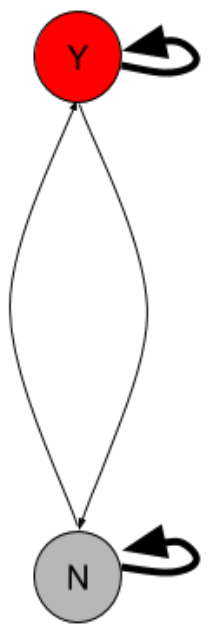

C.

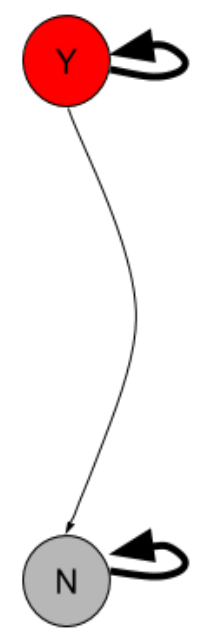

Figure S1.5: Generations since divergence and presence/absence of IBD are easy to classify. Arrows indicate model assignments. Arrows as in Figure 6. A) Confusion between different ages, 6,000 generations ("6") through $1,000,000$ generations ("1000"). B) Confusion between IBD present ("Y") and absent ("N") for 6,000-120,000 generations. C) As in B for 1,000,000 generations.

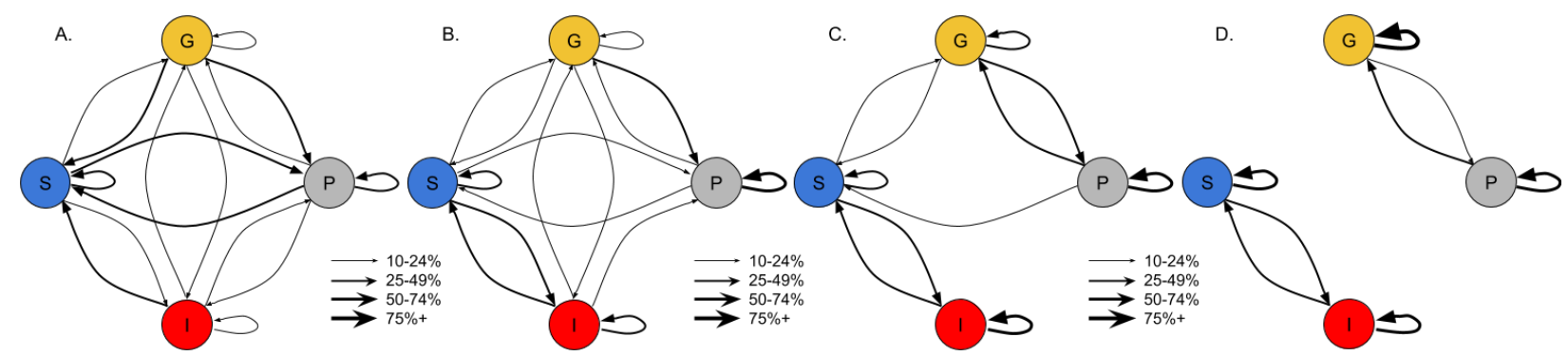

Figure S1.6: Phylogeographic structure is easy to classify after a long time since divergence, but not after a short time. Arrows and demographic prefixes ("P", "G", "I", and "S") as in Figure 6. A) 6,000 generations. B) 21,000 generations. C) 120,000 generations. D) 1,000,000 generations. 


\section{Appendix 2: Data Sources}

Aguillon, S. M., Campagna, L., Harrison, R. G., \& Lovette, I. J. (2018). A flicker of hope: Genomic data distinguish Northern Flicker taxa despite low levels of divergence. The Auk: Ornithological Advances, 135(3), 748-766.

Aiello-Lammens, M.E., Boria, R.A., Radosavljevic, A., Vilela, B., and Anderson, R.P. (2014). spThin: Functions for Spatial Thinning of Species Occurrence Records for Use in Ecological Models. R package version 0.1.0.

Andersen, J. J., \& Light, J. E. (2012). Phylogeography and subspecies revision of the hispid pocket mouse, Chaetodipus hispidus (Rodentia: Heteromyidae). Journal of Mammalogy, 93(4), 1195-1215.

Anderson, C. G., \& Greenbaum, E. (2012). Phylogeography of northern populations of the black-tailed rattlesnake (Crotalus molossus Baird and Girard, 1853), with the revalidation of C. ornatus Hallowell, 1854. Herpetological Monographs, 26(1), 19-57.

Ashton, K. G., \& de Queiroz, A. (2001). Molecular systematics of the western rattlesnake, Crotalus viridis (Viperidae), with comments on the utility of the D-loop in phylogenetic studies of snakes. Molecular Phylogenetics and Evolution, 21(2), 176-189.

Ayoub, N. A., \& Riechert, S. E. (2004). Molecular evidence for Pleistocene glacial cycles driving diversification of a North American desert spider, Agelenopsis aperta. Molecular Ecology, 13(11), 3453-3465.

Ball Jr, R. M., \& Avise, J. C. (1992). Mitochondrial DNA phylogeographic differentiation among avian populations and the evolutionary significance of subspecies. The Auk, 109(3), 626-636.

Belfiore, N. M., Liu, L., \& Moritz, C. (2008). Multilocus phylogenetics of a rapid radiation in the genus Thomomys (Rodentia: Geomyidae). Systematic Biology, 57(2), 294-310.

Bivand, R., and Rundel, C., (2017). rgeos: Interface to Geometry Engine - Open Source ('GEOS'). R package version 0.3-26.

Bivand, Roger S., Edzer Pebesma, and Virgilio Gómez-Rubio. (2013). Applied Spatial Data Analysis with R. Springer, New York.

Bryson Jr, R. W., García-Vázquez, U. O., \& Riddle, B. R. (2011). Phylogeography of Middle American gophersnakes: mixed responses to biogeographical barriers across the Mexican Transition Zone. Journal of Biogeography, 38(8), 1570-1584.

Bryson Jr, R. W., Jaeger, J. R., Lemos-Espinal, J. A., \& Lazcano, D. (2012). A multilocus perspective on the speciation history of a North American aridland toad (Anaxyrus punctatus). Molecular Phylogenetics and Evolution, 64(3), 393-400.

Bryson Jr, R. W., Murphy, R. W., Graham, M. R., Lathrop, A., \& Lazcano, D. (2011). Ephemeral Pleistocene woodlands connect the dots for highland rattlesnakes of the Crotalus intermedius group. Journal of Biogeography, 38(12), 2299-2310.

Bryson Jr, R. W., Riddle, B. R., Graham, M. R., Smith, B. T., \& Prendini, L. (2013). As old as the hills: montane scorpions in southwestern North America reveal ancient associations between biotic diversification and landscape history. PLoS One, 8(1), e52822.

Bryson Jr, R. W., Savary, W. E., \& Prendini, L. (2013b). Biogeography of scorpions in the Pseudouroctonus minimus complex (Vaejovidae) from south-western North America: implications of ecological specialization for pre-Quaternary diversification. Journal of Biogeography, 40(10), 1850-1860. 
Burbrink, F. T., \& Gehara, M. (2018). The biogeography of deep time phylogenetic reticulation. Systematic Biology, 67(5), 743-755.

Burbrink, F. T., Chan, Y. L., Myers, E. A., Ruane, S., Smith, B. T., \& Hickerson, M. J. (2016). Asynchronous demographic responses to Pleistocene climate change in Eastern Nearctic vertebrates. Ecology Letters, 19(12), 1457-1467.

Byrd, R. H., Lu, P., Nocedal, J., \& Zhu, C. (1995). A limited memory algorithm for bound constrained optimization. SIAM Journal on Scientific Computing, 16(5), 1190-1208.

Castellanos-Morales, G., Paredes-Torres, L. M., Gámez, N., Hernández-Rosales, H. S., Sánchez-de la Vega, G., Barrera-Redondo, J., ... Eguiarte, L. E. (2018). Historical biogeography and phylogeny of Cucurbita: insights from ancestral area reconstruction and niche evolution. Molecular Phylogenetics and Evolution, 128, 38-54.

Castoe, T. A., Spencer, C. L., \& Parkinson, C. L. (2007). Phylogeographic structure and historical demography of the western diamondback rattlesnake (Crotalus atrox): a perspective on North American desert biogeography. Molecular Phylogenetics and Evolution, 42(1), 193-212.

Chamberlain, S. (2017). spocc: Interface to Species Occurrence Data Sources. R package version 0.7.0.

Cheng, X., Khomtchouk, B., Matloff, N., \& Mohanty, P. (2018). Polynomial regression as an alternative to neural nets. arXiv, 1806.06850.

Cox et al., 2018

Dahn, H. A., Strickland, J. L., Osorio, A., Colston, T. J., \& Parkinson, C. L. (2018). Hidden diversity within the depauperate genera of the snake tribe Lampropeltini (Serpentes, Colubridae). Molecular Phylogenetics and Evolution, 129, 214-225.

Danecek, P., Auton, A., Abecasis, G., Albers, C. A., Banks, E., DePristo, M. A., ... Durbin, R. (2011). The variant call format and VCFtools. Bioinformatics, 27(15), 2156-2158.

Davis, M. A., Douglas, M. R., Collyer, M. L., \& Douglas, M. E. (2016). Deconstructing a species-complex: geometric morphometric and molecular analyses define species in the Western Rattlesnake (Crotalus viridis). PloS One, 11(1), e0146166.

Devitt, T. J. (2006). Phylogeography of the Western Lyresnake (Trimorphodon biscutatus): testing aridland biogeographical hypotheses across the Nearctic-Neotropical transition. Molecular Ecology, 15(14), 4387-4407.

Devitt, T. J., LaDuc, T. J., \& McGuire, J. A. (2008). The Trimorphodon biscutatus (Squamata: Colubridae) species complex revisited: a multivariate statistical analysis of geographic variation. Copeia, 2008(2), 370-387.

Douglas, M. E., \& Schuett, G. W. (2002). Phylogeography of the western rattlesnake (Crotalus viridis) complex, with emphasis on the Colorado Plateau. In G. W. Schuett, M. Hoggren, M. E. Douglas (Eds.), Biology of the Vipers (pp. 11-50). Eagle Mountain, UT: Eagle Mountain Publishing.

Ferguson, A. W., McDonough, M. M., Guerra, G. I., Rheude, M., Dragoo, J. W., Ammerman, L. K., \& Dowler, R. C. (2017). Phylogeography of a widespread small carnivore, the western spotted skunk (Spilogale gracilis) reveals temporally variable signatures of isolation across western North America. Ecology and Evolution, 7(12), 4229-4240.

Gray, D. A., Gutierrez, N. J., Chen, T. L., Gonzalez, C., Weissman, D. B., \& Cole, J. A. (2016). Species divergence in field crickets: genetics, song, ecomorphology, and pre-and postzygotic isolation. Biological Journal of the Linnean Society, 117(2), 192-205. 
Gugger, P. F., González-Rodríguez, A., Rodríguez-Correa, H., Sugita, S., \& Cavender-Bares, J. (2011). Southward Pleistocene migration of Douglas-fir into Mexico: phylogeography, ecological niche modeling, and conservation of 'rear edge' populations. New Phytologist, 189(4), 1185-1199.

Gugger, P. F., Sugita, S., \& Cavender-Bares, J. (2010). Phylogeography of Douglas-fir based on mitochondrial and chloroplast DNA sequences: testing hypotheses from the fossil record. Molecular Ecology, 19(9), 1877-1897.

Haenel, G. J. (2007). Phylogeography of the tree lizard, Urosaurus ornatus: responses of populations to past climate change. Molecular Ecology, 16(20), 4321-4334.

Haller, B. C., \& Messer, P. W. (2017). SLiM 2: Flexible, interactive forward genetic simulations. Molecular Biology and Evolution, 34(1), 230-240.

Haring, E., Däubl, B., Pinsker, W., Kryukov, A., \& Gamauf, A. (2012). Genetic divergences and intraspecific variation in corvids of the genus Corvus (Aves: Passeriformes: Corvidae)-a first survey based on museum specimens. Journal of Zoological Systematics and Evolutionary Research, 50(3), 230-246.

Hijmans, R.J. (2017). raster: Geographic Data Analysis and Modeling. R package version 2.6-7.

Hijmans, R.J., Cameron, S.E., Parra, J.L., Jones, P.G., and Jarvis, A. (2005). Very high resolution interpolated climate surfaces for global land areas. International Journal of Climatology, 25, 1965-1978.

Hijmans, R.J., Phillips, S., Leathwick, J., and Elith, J. (2017). dismo: Species Distribution Modeling. R package version 1.1-4.

Hoekstra, H. E., Krenz, J. G., \& Nachman, M. W. (2005). Local adaptation in the rock pocket mouse (Chaetodipus intermedius): natural selection and phylogenetic history of populations. Heredity, 94(2), 217-228.

Hosner, P. A., Braun, E. L., \& Kimball, R. T. (2015). Land connectivity changes and global cooling shaped the colonization history and diversification of New World quail (Aves: Galliformes: Odontophoridae). Journal of Biogeography, 42(10), 1883-1895.

Jaeger, J. R., Riddle, B. R., \& Bradford, D. F. (2005). Cryptic Neogene vicariance and Quaternary dispersal of the red-spotted toad (Bufo punctatus): insights on the evolution of North American warm desert biotas. Molecular Ecology, 14(10), 3033-3048.

Jezkova, T., Jaeger, J. R., Marshall, Z. L., \& Riddle, B. R. (2009). Pleistocene impacts on the phylogeography of the desert pocket mouse (Chaetodipus penicillatus). Journal of Mammalogy, 90(2), 306-320.

Johnsen, A., Kearns, A. M., Omland, K. E., \& Anmarkrud, J. A. (2017). Sequencing of the complete mitochondrial genome of the common raven Corvus corax (Aves: Corvidae) confirms mitogenome-wide deep lineages and a paraphyletic relationship with the Chihuahuan raven C. cryptoleucus. PLoS One, 12(10), e0187316.

Juang, C. F., \& Chen, T. M. (2007). Birdsong recognition using prediction-based recurrent neural fuzzy networks. Neurocomputing, 71(1-3), 121-130.

Kearns, A. M., Restani, M., Szabo, I., Schrøder-Nielsen, A., Kim, J. A., Richardson, H. M., ... Omland, K. E. (2018). Genomic evidence of speciation reversal in ravens. Nature Communications, 9(1), 906.

Klicka, J., Spellman, G. M., Winker, K., Chua, V., \& Smith, B. T. (2011). A phylogeographic and population genetic analysis of a widespread, sedentary North American bird: The Hairy Woodpecker (Picoides villosus). The Auk, 128(2), 346-362. 
Klicka, L. B., Kus, B. E., \& Burns, K. J. (2016). Conservation genomics reveals multiple evolutionary units within Bell's Vireo (Vireo bellii). Conservation Genetics, 17(2), 455-471.

LaDuc, T. J., \& Johnson, J. D. (2003). A taxonomic revision of Trimorphodon biscutatus vilkinsonii (Serpentes: Colubridae). Herpetologica, 59(3), 364-374.

Lamb, T., Jones, T. R., \& Wettstein, P. J. (1997). Evolutionary genetics and phylogeography of tassel-eared squirrels (Sciurus aberti). Journal of Mammalogy, 78(1), 117-133.

Latch, E. K., Heffelfinger, J. R., Fike, J. A., \& Rhodes Jr, O. E. (2009). Species-wide phylogeography of North American mule deer (Odocoileus hemionus): cryptic glacial refugia and postglacial recolonization. Molecular Ecology, 18(8), 1730-1745.

Leaché, A. D., \& McGuire, J. A. (2006). Phylogenetic relationships of horned lizards (Phrynosoma) based on nuclear and mitochondrial data: evidence for a misleading mitochondrial gene tree. Molecular Phylogenetics and Evolution, 39(3), 628-644.

Leache, A. D., \& Mulcahy, D. G. (2007). Phylogeny, divergence times and species limits of spiny lizards (Sceloporus magister species group) in western North American deserts and Baja California. Molecular Ecology, 16(24), 5216-5233.

Lee Jr, T. E., Riddle, B. R., \& Lee, P. L. (1996). Speciation in the desert pocket mouse (Chaetodipus penicillatus Woodhouse). Journal of Mammalogy, 77(1), 58-68.

Liebherr, J. K. (1986). Comparison of genetic variation in two carabid beetles (Coleoptera) of differing vagility. Annals of the Entomological Society of America, 79(3), 424-433.

Lovette, I. J., Arbogast, B. S., Curry, R. L., Zink, R. M., Botero, C. A., Sullivan, J. P., ... Bermingham, E. (2012). Phylogenetic relationships of the mockingbirds and thrashers (Aves: Mimidae). Molecular Phylogenetics and Evolution, 63(2), 219-229.

Manthey, J. D., Geiger, M., \& Moyle, R. G. (2017). Relationships of morphological groups in the northern flicker superspecies complex (Colaptes auratus \& C. chrysoides). Systematics and Biodiversity, 15(3), 183-191.

Manthey, J. D., Klicka, J., \& Spellman, G. M. (2011). Isolation-driven divergence: speciation in a widespread North American songbird (Aves: Certhiidae). Molecular Ecology, 20(20), 4371-4384.

Mantooth, S. J., Hafner, D. J., Bryson Jr, R. W., \& Riddle, B. R. (2013). Phylogeographic diversification of antelope squirrels (Ammospermophilus) across North American deserts. Biological Journal of the Linnean Society, 109(4), 949-967.

McAliley, L. R., O'Neill, M. B., \& Baker, R. J. (2007). Molecular evidence for genetic subdivisions in the desert shrew, Notiosorex crawfordi. The Southwestern Naturalist, 410-417.

Moore, W. S., Graham, J. H., \& Price, J. T. (1991). Mitochondrial DNA variation in the northern flicker (Colaptes auratus, Aves). Molecular Biology and Evolution, 8, 327-344.

Mott, B. M., Gadau, J., \& Anderson, K. E. (2015). Phylogeography of Pogonomyrmex barbatus and $P$. rugosus harvester ants with genetic and environmental caste determination. Ecology and Evolution, 5(14), 2798-2826.

Mulcahy, D. G. (2008). Phylogeography and species boundaries of the western North American Nightsnake (Hypsiglena torquata): revisiting the subspecies concept. Molecular Phylogenetics and Evolution, 46(3), 1095-1115. 
Mulcahy, D. G., \& Macey, J. R. (2009). Vicariance and dispersal form a ring distribution in nightsnakes around the Gulf of California. Molecular Phylogenetics and Evolution, 53(2), 537-546.

Muscarella, R., Galante, P.J., Soley-Guardia, M., Boria, R.A., Kass, J., Uriarte, M. and R.P. Anderson (2014). ENMeval: An R package for conducting spatially independent evaluations and estimating optimal model complexity for ecological niche models. Methods in Ecology and Evolution, 5, 1198-1205.

Myers, E. A., Bryson Jr, R. W., Hansen, R. W., Aardema, M. L., Lazcano, D., \& Burbrink, F. T. (2019a). Exploring Chihuahuan Desert diversification in the gray-banded kingsnake, Lampropeltis alterna (Serpentes: Colubridae). Molecular Phylogenetics and Evolution, 131, 211-218.

Myers, E. A., Burgoon, J. L., Ray, J. M., Martínez-Gómez, J. E., Matías-Ferrer, N., Mulcahy, D. G., \& Burbrink, F. T. (2017a). Coalescent species tree inference of Coluber and Masticophis. Copeia, 105(4), 640-648.

Myers, E. A., Hickerson, M. J., \& Burbrink, F. T. (2017b). Asynchronous diversification of snakes in the North American warm deserts. Journal of Biogeography, 44(2), 461-474.

Myers, E. A., Xue, A. T., Gehara, M., Cox, C. L., Davis Rabosky, A. R., Lemos-Espinal, J., ... Burbrink, F. T. (2019b). Environmental heterogeneity and not vicariant biogeographic barriers generate community-wide population structure in desert-adapted snakes. Molecular Ecology, 28(20), 4535-4548.

Nam, K., Mugal, C., Nabholz, B., Schielzeth, H., Wolf, J. B., Backström, N., ... Clayton, D. F. (2010). Molecular evolution of genes in avian genomes. Genome Biology, 11(6), R68.

Nason, J. D., Hamrick, J. L., \& Fleming, T. H. (2002). Historical vicariance and postglacial colonization effects on the evolution of genetic structure in Lophocereus, a Sonoran Desert columnar cactus. Evolution, 56(11), 2214-2226.

O'Connell, K. A., Streicher, J. W., Smith, E. N., \& Fujita, M. K. (2017). Geographical features are the predominant driver of molecular diversification in widely distributed North American whipsnakes. Molecular Ecology, 26(20), 5729-5751.

Omland, K. E., Baker, J. M., \& Peters, J. L. (2006). Genetic signatures of intermediate divergence: population history of Old and New World Holarctic ravens (Corvus corax). Molecular Ecology, 15(3), 795-808.

Omland, K. E., Tarr, C. L., Boarman, W. I., Marzluff, J. M., \& Fleischer, R. C. (2000). Cryptic genetic variation and paraphyly in ravens. Proceedings of the Royal Society of London. Series B: Biological Sciences, 267(1461), 2475-2482.

Orange, D. I., Riddle, B. R., \& Nickle, D. C. (1999). Phylogeography of a wide-ranging desert lizard, Gambelia wislizenii (Crotaphytidae). Copeia, 267-273.

Pebesma, E.J., and Bivand, R.S. 2005. Classes and methods for spatial data in R. R News, 5(2), 9-13.

Phillips, S.J., Anderson, R.A., Schapire, R.E. (2006). Maximum entropy modeling of species geographic distributions. Ecological Modelling, 190, 231-259.

Pook, C. E., Wüster, W., \& Thorpe, R. S. (2000). Historical biogeography of the western rattlesnake (Serpentes: Viperidae: Crotalus viridis), inferred from mitochondrial DNA sequence information. Molecular Phylogenetics and Evolution, 15(2), 269-282. 
Provost, K. L., Mauck III, W. M., \& Smith, B. T. (2018). Genomic divergence in allopatric Northern Cardinals of the North American warm deserts is linked to behavioral differentiation. Ecology and Evolution, 8(24), 12456-12478.

Pulgarín-R, P. C., \& Burg, T. M. (2012). Genetic signals of demographic expansion in downy woodpecker (Picoides pubescens) after the last North American glacial maximum. PLoS One, 7(7), e40412.

Pulgarín-Restrepo, P. C. (2011). The population history of the downy woodpecker (Picoides pubescens) in North America: insights from genetics, ecological niche modeling and bioacoustics. (Master's Thesis University of Lethbridge, Lethbridge, Alberta, Canada).

Retrieved from http://opus.uleth.ca/bitstream/handle/10133/2613/PULGARIN_PAULO MSC 2011.pdf

Pyron, R. A., \& Burbrink, F. T. (2009). Lineage diversification in a widespread species: roles for niche divergence and conservatism in the common kingsnake, Lampropeltis getula. Molecular Ecology, 18(16), 3443-3457.

Rebernig, C. A., Schneeweiss, G. M., Bardy, K. E., Schoenswetter, P., Villasenor, J. L., Obermayer, R., ... Weiss-Schneeweiss, H. (2010). Multiple Pleistocene refugia and Holocene range expansion of an abundant southwestern American desert plant species (Melampodium leucanthum, Asteraceae). Molecular Ecology, 19(16), 3421-3443.

Riddle, B. R., Hafner, D. J., \& Alexander, L. F. (2000a). Comparative phylogeography of Baileys' pocket mouse (Chaetodipus baileyi) and the Peromyscus eremicus species group: historical vicariance of the Baja California peninsular desert. Molecular Phylogenetics and Evolution, 17(2), 161-172.

Riddle, B. R., Hafner, D. J., \& Alexander, L. F. (2000b). Phylogeography and systematics of the Peromyscus eremicus species group and the historical biogeography of North American warm regional deserts. Molecular Phylogenetics and Evolution, 17(2), 145-160.

Riddle, B. R. (1995). Molecular biogeography in the pocket mice (Perognathus and Chaetodipus) and grasshopper mice (Onychomys): the late Cenozoic development of a North American aridlands rodent guild. Journal of Mammalogy, 76(2), 283-301.

Riddle, B. R., \& Honeycutt, R. L. (1990). Historical biogeography in North American arid regions: an approach using mitochondrial-DNA phylogeny in grasshopper mice (genus Onychomys). Evolution, 44(1), 1-15.

Rodriguez, R. M., \& Ammerman, L. K. (2004). Mitochondrial DNA divergence does not reflect morphological difference between Myotis californicus and Myotis ciliolabrum. Journal of Mammalogy, 85(5), 842-851.

Rojas-Soto, O. R. (2003). Geographic variation of the curve-billed thrasher (Toxostoma curvirostre) complex. The Auk, 120(2), 311-322.

Rojas-Soto, O. R., De Los Monteros, A. E., \& Zink, R. M. (2007). Phylogeography and patterns of differentiation in the curve-billed thrasher. The Condor, 109(2), 456-463.

Rosenthal, J., \& Forstner, M. R. J. (2004). Effects of Plio-Pleistocene barrier on Chihuahua Desert herpetofauna. In Proceedings of the sixth symposium on the natural resources of the Chihuahua Desert region, 2004 (pp. 269-82).

Schield, D. R., Adams, R. H., Card, D. C., Corbin, A. B., Jezkova, T., Hales, N. R., ... García, G. C. (2018). Cryptic genetic diversity, population structure, and gene flow in the Mojave Rattlesnake (Crotalus scutulatus). Molecular Phylogenetics and Evolution, 127, 669-681. 
Schield, D. R., Adams, R. H., Card, D. C., Perry, B. W., Pasquesi, G. M., Jezkova, T., ... Fujita, M. K. (2017). Insight into the roles of selection in speciation from genomic patterns of divergence and introgression in secondary contact in venomous rattlesnakes. Ecology and Evolution, 7(11), 3951-3966.

Schield, D. R., Card, D. C., Adams, R. H., Jezkova, T., Reyes-Velasco, J., Proctor, F. N., ... Castoe, T. A. (2015). Incipient speciation with biased gene flow between two lineages of the Western Diamondback Rattlesnake (Crotalus atrox). Molecular Phylogenetics and Evolution, 83, 213-223.

Serb, J. M., Phillips, C. A., \& Iverson, J. B. (2001). Molecular phylogeny and biogeography of Kinosternon flavescens based on complete mitochondrial control region sequences. Molecular Phylogenetics and Evolution, 18(1), 149-162.

Sinclair, E. A., Bezy, R. L., Bolles, K., Camarillo R, J. L., Crandall, K. A., \& Sites, Jr, J. W. (2004). Testing species boundaries in an ancient species complex with deep phylogeographic history: genus Xantusia (Squamata: Xantusiidae). The American Naturalist, 164(3), 396-414.

Smith, B. T., Bryson Jr, R. W., Mauck III, W. M., Chaves, J., Robbins, M. B., Aleixo, A., \& Klicka, J. (2018). Species delimitation and biogeography of the gnatcatchers and gnatwrens (Aves: Polioptilidae). Molecular Phylogenetics and Evolution, 126, 45-57.

Smith, B. T., Escalante, P., Baños, B. E. H., Navarro-Sigüenza, A. G., Rohwer, S., \& Klicka, J. (2011). The role of historical and contemporary processes on phylogeographic structure and genetic diversity in the Northern Cardinal, Cardinalis cardinalis. BMC Evolutionary Biology, 11(1), 136.

Smith, C. I., \& Farrell, B. D. (2005). Phylogeography of the longhorn cactus beetle Moneilema appressum LeConte (Coleoptera: Cerambycidae): was the differentiation of the Madrean sky islands driven by Pleistocene climate changes? Molecular Ecology, 14(10), 3049-3065.

Spellman, G. M., \& Klicka, J. (2007). Phylogeography of the white-breasted nuthatch (Sitta carolinensis): diversification in North American pine and oak woodlands. Molecular Ecology, 16(8), 1729-1740.

Stevison, L. (2014, June 4). vef-conversion-tools 1.0 (Version 1.0). Zenodo. http://doi.org/10.5281/zenodo.10288

Streicher, J. W., Cox, C. L., Campbell, J. A., Smith, E. N., \& de Sá, R. O. (2012). Rapid range expansion in the Great Plains narrow-mouthed toad (Gastrophryne olivacea) and a revised taxonomy for North American microhylids. Molecular Phylogenetics and Evolution, 64(3), 645-653.

Sukumaran, J., Economo, E. P., \& Lacey Knowles, L. (2016). Machine learning biogeographic processes from biotic patterns: a new trait-dependent dispersal and diversification model with model choice by simulation-trained discriminant analysis. Systematic Biology, 65(3), 525-545.

Sullivan, B. L., Wood, C. L., Iliff, M. J., Bonney, R. E., Fink, D., and Kelling, S. (2009). eBird: A citizen-based bird observation network in the biological sciences. Biological Conservation, 142(10), 2282-2292.

Teutimez, M. R. (2012). The cactus wren (Campylorhynchus brunneicapillus) in southern California: haplotype comparisons among coastal and inland populations. (Master's Thesis). Retrieved from ProQuest Dissertations and Theses database. (UMI No. 1517542) 
Vázquez-Miranda, H., Griffin, J. A., Sheppard, J. M., Herman, J. M., Rojas-Soto, O., \& Zink, R. M. (2017). Morphological and molecular evolution and their consequences for conservation and taxonomy in the Le Conte's thrasher Toxostoma lecontei. Journal of Avian Biology, 48(7), 941-954.

Venables, W. N. and Ripley, B. D. (2002) Modern Applied Statistics with S. Springer, New York.

Walpole, D. K., Davis, S. K., \& Greenbaum, I. F. (1997). Variation in mitochondrial DNA in populations of Peromyscus eremicus from the Chihuahuan and Sonoran deserts. Journal of Mammalogy, 78(2), 397-404.

Webb, W. C., Marzluff, J. M., \& Omland, K. E. (2011). Random interbreeding between cryptic lineages of the Common Raven: evidence for speciation in reverse. Molecular Ecology, 20(11), 2390-2402.

Wei, X. S., Xie, C. W., Wu, J., \& Shen, C. (2018). Mask-CNN: Localizing parts and selecting descriptors for fine-grained bird species categorization. Pattern Recognition, 76, 704-714.

Weyandt, S. E., \& Van Den Bussche, R. A. (2007). Phylogeographic structuring and volant mammals: the case of the pallid bat (Antrozous pallidus). Journal of Biogeography, 34(7), 1233-1245.

Wickham, H., Francois, R., Henry, L., and Müller, K. (2017). dplyr: A Grammar of Data Manipulation. R package version 0.7.4.

Wilson, J. S., \& Pitts, J. P. (2008). Revision of velvet ant genus Dilophotopsis Schuster (Hymenoptera: Mutillidae) by using molecular and morphological data, with implications for desert biogeography. Annals of the Entomological Society of America, 101(3), 514-524.

Wilson, J. S., \& Pitts, J. P. (2010). Phylogeographic analysis of the nocturnal velvet ant genus Dilophotopsis (Hymenoptera: Mutillidae) provides insights into diversification in the Nearctic deserts. Biological journal of the Linnean Society, 101(2), 360-375.

Zink, R. M. (1996). Comparative phylogeography in North American birds. Evolution, 50(1), 308-317.

Zink, R. M. (2014). Homage to Hutchinson, and the role of ecology in lineage divergence and speciation. Journal of Biogeography, 41(5), 999-1006.

Zink, R. M., \& Blackwell-Rago, R. C. (2000). Species limits and recent population history in the Curve-billed Thrasher. The Condor, 102(4), 881-886.

Zink, R. M., \& Klicka, J. (2000). Avian evolution during the Pleistocene in North America. In M. Kato (Ed.), The Biology of biodiversity (pp. 275-288). Tokyo: Springer.

Zink, R. M., Blackwell, R. C., \& Rojas-Soto, O. (1997). Species limits in the Le Conte's Thrasher. The Condor, 99(1), 132-138.

Zink, R. M., Dittmann, D. L., Klicka, J., \& Blackwell-Rago, R. C. (1999). Evolutionary patterns of morphometrics, allozymes, and mitochondrial DNA in thrashers (genus Toxostoma). The Auk, 116

Zink, R. M., Kessen, A. E., Line, T. V., \& Blackwell-Rago, R. C. (2001). Comparative phylogeography of some aridland bird species. The Condor, 103(1), 1-10. 
bioRxiv preprint doi: https://doi.org/10.1101/2020.06.17.157842; this version posted June 18, 2020. The copyright holder for this preprint (which was not certified by peer review) is the author/funder. All rights reserved. No reuse allowed without permission. 